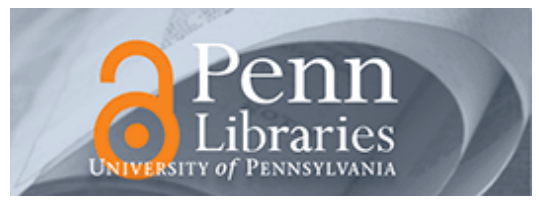

University of Pennsylvania

ScholarlyCommons

Accounting Papers

Wharton Faculty Research

$5-2013$

\title{
What Do Management Earnings Forecasts Convey About the Macroeconomy?
}

Samuel B. Bonsall IV

Zahn Bozanic

Paul E. Fischer

University of Pennsylvania

Follow this and additional works at: https://repository.upenn.edu/accounting_papers

Part of the Accounting Commons

\section{Recommended Citation}

Bonsall, S. B., Bozanic, Z., \& Fischer, P. E. (2013). What Do Management Earnings Forecasts Convey About the Macroeconomy?. Journal of Accounting Research, 51 (2), 225-266. http://dx.doi.org/10.1111/ 1475-679X.12007

This paper is posted at ScholarlyCommons. https://repository.upenn.edu/accounting_papers/68

For more information, please contact repository@pobox.upenn.edu. 


\title{
What Do Management Earnings Forecasts Convey About the Macroeconomy?
}

\begin{abstract}
We decompose quantitative management earnings forecasts into macroeconomic and firm-specific components to determine the extent to which voluntary disclosure provided by management has macroeconomic information content. We provide evidence that the forecasts of bellwether firms, which are defined as firms in which macroeconomic news explains the greatest amount of variation in the forecasts, provide timely information to the market about the macroeconomy when bundled with earnings announcements. Further, we show that bellwether firms provide timely information about both industryspecific events and broader economic events. Finally, we document that the macroeconomic news in individual forecasts is more pronounced for bad news and point forecasts.
\end{abstract}

Keywords

voluntary disclosure, management earnings forecasts, bellwether firms, macroeconomic risk

Disciplines

Accounting 


\section{What Do Management Earnings Forecasts Convey About the Macroeconomy?*}

Samuel B. Bonsall, IV Fisher College of Business The Ohio State University

Columbus, OH 43210
Zahn Bozanic

Fisher College of Business

The Ohio State University

Columbus, $\mathrm{OH} 43210$
Paul E. Fischer The Wharton School University of Pennsylvania

Philadelphia, PA 19104

January 2013

\footnotetext{
${ }^{*}$ Corresponding author: bozanic_1@fisher.osu.edu. Accepted by Douglas Skinner. We would like to thank an anonymous referee, Andrew Acito, Dan Givoly, Luzi Hail, Brian Miller, Karl Muller, Darren Roulstone, Abbie Smith, Andy Van Buskirk, Greg Waymire, and conference participants at the 22nd Annual Conference on Financial Economics and Accounting, the 2012 FARS Midyear Meeting, and the 2012 Journal of Accounting Research Conference for helpful comments and suggestions.
} 
What Do Management Earnings Forecasts Convey About the Macroeconomy?

\begin{abstract}
We decompose quantitative management earnings forecasts into macroeconomic and firm-specific components to determine the extent to which voluntary disclosure provided by management has macroeconomic information content. We provide evidence that the forecasts of bellwether firms, which are defined as firms in which macroeconomic news explains the greatest amount of variation in the forecasts, provide timely information to the market about the macroeconomy when bundled with earnings announcements. Further, we show that bellwether firms provide timely information about both industry-specific events and broader economic events. Finally, we document that the macroeconomic news in individual forecasts is more pronounced for bad news and point forecasts.
\end{abstract}

Keywords: Voluntary disclosure, management earnings forecasts, bellwether firms, macroeconomic risk

JEL Classifications: E44, G14, M41 


\section{Introduction}

One would hardly confuse corporate executives with professional macroeconomic forecasters. Unlike economic forecasters, executives must make actual operating, investing, and financing decisions and, at best, they may rely upon the insights of the former to aid in their decision-making. If their firms are subject to macroeconomic risks, however, corporate executives may indirectly be privy to timely information about the underlying macroeconomic state that could, in turn, be transmitted to the broader market via management earnings forecasts. In this study, we examine whether management earnings forecasts convey timely information about the macroeconomic state.

The working assumption in the voluntary disclosure literature is that managers have private information, which is strategically communicated to investors and analysts via voluntary disclosures like management earnings forecasts. ${ }^{1}$ From an empirical perspective, however, the nature of the private information communicated by management is not well understood. In this study, we add to the understanding of management's information advantage by assessing whether some of the information communicated via management earnings forecasts pertains to undiversifiable macroeconomic risks, as opposed to diversifiable firm or industry specific risks. If management earnings forecasts do provide timely macroeconomic information, that observation would, in turn, contribute to the broader understanding of how macroeconomic information is disseminated throughout the economy.

Whether or not management's earnings forecasts are a timely source of macroeconomic information is far from clear. More specifically, managers may not have the expertise necessary to generate timely information about macroeconomic outcomes. For example, Ben-David, Graham, and Harvey (2012) document that managers exhibit significant miscalibration in their predictions of stock market returns and Hutton, Lee, and Shu (2012) document that analyst forecasts are more accurate than management forecasts when a firm's prospects are tied to macroeconomic factor realizations. Both of these observations might cast doubt on management's ability to provide timely macroeconomic information via their earnings forecasts. On the other hand, management earnings forecasts may still convey macroeconomic information even if managers do not fully process and impound their private macroeconomic information into their forecasts.

\footnotetext{
${ }^{1}$ See, for example, Dye (1985) or Verrecchia (1983).
} 
In our initial analysis, we decompose realized earnings into two components, a macroeconomic component that is determined by proxies for macroeconomic state variables and a firm-specific component. To determine the nature of the information held by management at the time of the earnings forecast, we then regress the earnings forecast on estimates of the macroeconomic and firm-specific components of the earnings realization being forecast to estimate how much of the variation in the earnings forecast is attributable to the macroeconomic and firm-specific components of earnings. We compare the ratio of the percentage of variation in the forecast attributable to the macroeconomic component over the percentage attributable to the firm-specific component to the same ratio for earnings. The mean (median) of the difference in the two ratios is positive (positive) and significantly (insignificantly) different from zero suggesting that the private information underlying management forecasts is, perhaps, slightly more weighted towards the macroeconomic state relative to the impact of the macroeconomic state on earnings itself. Finally, we show there is significant cross-sectional variation in the extent to which the variation in the forecasts are explained by the macroeconomic component of earnings, which suggests that some firms' forecasts contain significantly more information about the macroeconomic state.

Even though management forecasts contain macroeconomic information in addition to firmspecific information, we do not know whether the forecasts provide timely information regarding the macroeconomic state. There is substantial evidence that security market prices are leading indicators of the macroeconomic state, where that state is defined by aggregate statistics such as GDP, industrial production, and investment (see, for example, Barro, 1990; Fama, 1981, 1990), and consistent with that evidence, the stock market is often viewed as a leading economic indicator for entities tracking the economy, such as The Conference Board. One argument put forth for why security markets lead the economy is that security market participants price securities based upon the information they have about future real economic activity. Management forecasts might be a source of such information either because they are forecasts of a component characterizing the macroeconomic state (i.e., corporate profits are a direct component of GDP under one computation approach for that statistic) or because they are correlated with other components characterizing the macroeconomic state. ${ }^{2}$

We employ a short-window event study analysis to test whether management earnings fore-

\footnotetext{
${ }^{2}$ For information regarding how macroeconomic statistics are measured, see McCulla and Smith (2007).
} 
casts provide timely macroeconomic information. In our event study approach, we test whether individual forecast surprises are associated with market portfolio returns, excluding the return of the forecasting firm, during short windows around the forecast announcement date. Consistent with management forecasts providing timely macroeconomic information, and after controlling for earnings announcements as well as a number of other lagged macroeconomic variables, we find that firms' forecasts are associated with market returns during the forecast announcement window. We further hypothesize that the market's response to a firm's forecast should be greater if the forecast contains more macroeconomic information, as measured by the estimate of the macroeconomic information impounded into forecasts. We provide strong evidence consistent with this hypothesis. In fact, the market return during the forecast announcement window is significant only for firms considered to possess high macroeconomic information content in their forecasts.

In addition to assessing whether forecasts contain timely macroeconomic information, we assess whether the macroeconomic information in forecasts is due to the forecasts reflecting undiversifiable shocks just affecting a significant industry in the economy or shocks broadly affecting many industries in the economy. To do so, we divide the market portfolio into two sub-portfolios for each forecast: the portfolio of firms within the same industry as the forecasting firm and those outside the "division" of the forecasting firm, as defined by the Department of Labor. ${ }^{3}$ We document that the association between forecast surprise and coincident returns to both sub-portfolios are significant, which is consistent with at least some forecasts containing macroeconomic news relevant to many industries. We also provide some evidence that the magnitude of the return for the portfolio of firms within the same industry is more pronounced than the portfolio comprised of the remainder of the market, which is consistent with macroeconomic information being somewhat more relevant for the disclosing firm's industry.

We conduct additional analysis on particular attributes of high macroeconomic information content forecasts to assess whether those attributes are associated with the aggregate market response. Prior literature examining individual firms' stock price responses to forecasts finds that bad news and point forecasts are associated with greater stock price responses than good news and range forecasts, respectively. The former finding is attributed to litigation concerns prompting

\footnotetext{
${ }^{3}$ I.e., those firms within the 4-digit SIC code vs. those firms outside the major SIC division, respectively. Please see http://www.osha.gov/pls/imis/sic_manual.html for further detail.
} 
more timely revelation of bad news and the latter to management employing a forecast range to indicate the precision of their information. Because we believe the macroeconomic content of a forecast is unlikely to be significantly tied to forecasting incentives, we expect that similar results should apply to aggregate market responses to forecasts. Consistent with our expectations, we find that bad news forecasts and point forecasts are both associated with greater price movements in the broader market.

Given that macroeconomic uncertainty is priced, the association between forecast news and coincident returns that we document could be attributed to changes in uncertainty regarding future cash flows as well as changes in the expectations of those cash flows. Consequently, we consider implied volatilities as measured by the Chicago Board Options Exchange Volatility Index (VIX) to ascertain whether the forecasts are associated with changes in uncertainty. We find that the VIX is negatively related to the forecast surprise for firms with high macroeconomic content forecasts, which suggests that good (bad) forecast news is associated with a(n) reduction (increase) in expected future aggregate volatility. Furthermore, we find the magnitude of the VIX change around management forecasts is larger for bad news than for good news. Hence, it appears that the macroeconomic information content pertains to uncertainty regarding future cash flows in a manner consistent with the short window portfolio returns tests (i.e., good news implies less future volatility, which implies a positive equity price response).

The remainder of the paper proceeds as follows. Section 2 discusses related literature and Section 3 details our sample selection procedure. Section 4 presents a simple analytical framework and some preliminary analysis of the macroeconomic information in management forecasts. Section 5 provides the core of our empirical analysis regarding the timeliness of macroeconomic information conveyed by management forecasts. Section 6 presents some supplemental analysis prior to concluding in Section 7 .

\section{Prior Literature}

Anilowski et al. (2007) provide the most pertinent antecedent to this paper. They find aggregate earnings guidance, particularly downward guidance, is associated with aggregate earnings news and

they present some "weak evidence" that aggregate earnings guidance is associated with monthly 
market returns but not quarterly market returns. In their analysis, they conclude by considering whether management earnings forecasts by individual bellwether firms, which are defined as large firms, are associated with movements in aggregate stock prices during the forecast announcement window, which is directly related to the information event approach adopted in our study. They provide evidence that qualitative, as opposed to quantitative, guidance for these large firms has an association with aggregate market returns.

In contrast to aggregate firm forecasts studied by Anilowski et al. (2007), our analysis begins with a focus on individual firm forecasts. We structure some of our analysis, however, around a notion consistent with the bellwether firms identified by Anilowski et al. (2007) except we take a different approach in identifying such firms. In particular, we begin with the premise that some firms naturally have greater exposure to macroeconomic risk factors and expect that the quantitative guidance provided by such firms will have greater associations with announcement window market returns than other firms. Our finding regarding the forecasts of firms with higher levels of macroeconomic information content suggests an avenue for refining the notion of a bellwether firm. Specifically, Anilowski et al. (2007) find that qualitative disclosures by large firms, which they refer to as bellwether firms, are associated with disclosure announcement window market returns. One explanation for their finding is that size is a proxy for the macroeconomic information content in the disclosures. However, we find that firms with forecasts having higher macroeconomic information content tend to be slightly smaller, on average. In addition, incremental to our macroeconomic information metric, size does not explain the market response to macroeconomic information contained in the forecasts, which further suggests that size may not adequately proxy for macroeconomic information content.

Our study also relates to research about intra-industry spillover effects of disclosures. ${ }^{4}$ The most related paper in that stream is Baginski (1987), which focuses on intra-industry spillover effects of management forecasts and finds that forecast surprises for a firm are positively associated with coincident returns for other firms in the forecasting firm's industry. While our study focuses on broader macroeconomic shocks and, accordingly, considers the possibility of inter-industry spillover effects (Shivakumar, 2010), the intuition underlying our study is analogous to that considered in the

\footnotetext{
${ }^{4}$ See, for example, Baginski (1987), Clinch and Sinclair (1987), Foster (1981), Lang and Lundholm (1996), Pownall and Waymire (1989), and Thomas and Zhang (2008).
} 
intra-industry spillover literature. For example, an earnings forecast by one firm in an industry may influence returns of other firms in the same industry because the forecast provides new information regarding industry-specific events. Our analysis suggests that some of that news involves a broader information transfer.

Finally, our study is relates to research examining the extent to which the news in aggregate earnings reflects macroeconomic risks. Some research in this stream of literature, including Campbell (1991) and Vuolteenaho (2002), suggests that the news in earnings may be largely diversifiable, which would call into question whether individual forecasts of earnings would even have macroeconomic information content, while other studies, including Brown and Ball (1967), Fama (1990), Schwert (1990), Sadka (2007), and Ball et al. (2009), suggest otherwise. ${ }^{5}$ Within this stream of literature, the approach taken in our study is perhaps closest to Ball et al. (2009). Similar to one aspect of that study, we focus on common factors affecting earnings, although we do so by ex-ante identifying observable proxies for common factors in the spirit of Chen et al. (1986) whereas they use principal components analysis to empirically derive common earnings factors. More importantly, our study, which focuses on the macroeconomic information content of individual disclosures, as opposed to whether earnings risk is systematic and priced, adds to the insights in that literature by demonstrating that some of the macroeconomic news contained in earnings is revealed in a timely manner through management forecasts.

\section{Sample}

We conduct our primary analysis using a sample of 16,824 firm-quarters (974 firms) over the period 2001 - 2008. The sample period corresponds to the increased availability in the early 2000s of management forecast data from Thomson Financial's Company Issued Guidance (CIG) database and the period following the passage of Regulation FD. We obtain market return data from CRSP, VIX data from the CBOE, and firm financial information from Compustat. We retain the first quarterly earnings forecast from the CIG database made in quarter $t$ for quarter $t+1$. To estimate our proxy for macroeconomic information content, we require at least ten quarterly observations

\footnotetext{
${ }^{5}$ Indeed, Ball et al. (2009) state that "...the two components of price, returns and cash flows, may be jointly driven by common economic factors" and, given the high correlation between cash flow risk and return risk "...it may not be feasible to identify separate effects of cash flow news and returns news."
} 
per firm. After matching analyst earnings forecast data to management forecast data and requiring at least one analyst forecast to calculate earnings surprise, we arrive at our final sample.

Some of our empirical analysis requires that we characterize either the realization or expectation of the macroeconomic state. To do so we adopt an approach similar to that used by Chen et al. (1986) and employ various macroeconomic statistics as proxies for the macroeconomic factors (i.e., $M$ in the analytical framework) characterizing the macroeconomic state. ${ }^{6}$ Specifically, we employ the following variables as proxies: Moody's Aaa corporate bond yield (BOND), the consumer price index inflation rate (CPI), housing starts (HOUSING), the index of industrial production (INDPROD), real gross domestic product (RGDP), the three-month treasury bill rate (TBILL), the ten-year treasury bond rate (TBOND), and the unemployment rate (UNEMP). These data are obtained from the Federal Reserve Bank of Philadelphia's Survey of Professional Forecasters. We use the forecasts made in the quarter prior to the announcement date for the current quarter and the first vintage available for the realizations.

\section{Preliminary Analysis}

To provide some structural motivation, we begin by presenting a simple analytical framework that provides insight into how we interpret the findings of our preliminary empirical analysis on the macroeconomic information in management forecasts. We then discuss how we identify firms with management forecasts that have high macroeconomic information content relative to those of other firms. Finally, we compare the characteristics of firms with high macroeconomic information content forecasts to those of other forecasting firms.

\subsection{Analytical Framework}

Consider a firm whose earnings, $e$, are determined by macroeconomic factor realizations and a firm-specific shock realization:

$$
e=\mu_{e}+B^{\prime} M+m
$$

\footnotetext{
${ }^{6}$ The approach used by Chen et al. (1986) to study the relationship between macroeconomic variables and stock returns has also been adopted by other researchers. See Christofferson et al. (2002), Flannery and Protopapadakis (2002), and Liu and Zhang (2008) for examples.
} 
where $\mu_{e}$ is a constant, $M$ is a vector of macroeconomic factor realizations, $B$ is the sensitivity of the firm's earnings to the macroeconomic factor, and $m$ represents the impact of firm-specific shocks on earnings. $B^{\prime} M$ and $m$ are mean 0 independent normally distributed random variables with respective variances $V$ and $v$. Management privately obtains some information about $e$ that is represented by the realization of a random variable $y$, where $y$ is normally distributed with mean 0 , variance $s$, and covariances with $B^{\prime} M$ and $m$ of $C$ and $c$ respectively. We represent management's information with one aggregate statistic to reflect the idea that management observes events that are potentially influenced by both macroeconomic and firm-specific outcomes. For example, management may observe an unexpected increase in sales orders, which could be due in part to macroeconomic demand effects and/or firm-specific sales force effects.

The manager's forecasting strategy, $f$, is assumed to be linear in his information $y$ :

$$
f=\mu_{f}+b y+n
$$

where $\mu_{f}$ is a constant, $b$ is a constant, and $n$ is a normally distributed random variable with mean 0 and variance $\sigma$ that is independent of all other random variables. Note that we have not constrained the manager's forecast to be his expectation of earnings, which is not required for the forecast to be informative. If the manager's forecast equals his expectation of earnings, however, the forecast parameters equal $\mu_{f}=\mu_{e}, b=\frac{C+c}{s}$, and the variance of $n, \sigma$, is zero (i.e., $n=0$ ). If the manager's forecast is biased (deviates from the statistical expectation), the unconditional expected bias equals $\mu_{f}-\mu_{e}$, and the bias conditional upon $y$ and $n$ is $\mu_{f}-\mu_{e}+\left(b-\frac{C+c}{s}\right) y+n$.

\subsection{Empirical Framework}

Our empirical approach for identifying the extent to which a firm's forecasts reflect macroeconomic factor realizations stems directly from our analytic framework. We first decompose earnings into two components by regressing firms' earnings realizations on a proxy vector, $\hat{M}$, for the macroeconomic 
factor realizations, $M$, to obtain estimates of $\mu_{e}, B$ and $m$, which are denoted $\hat{\mu}_{e}, \hat{B}$ and $\hat{m}:^{7}$

$$
e=\hat{\mu}_{e}+\hat{B}^{\prime} \hat{M}+\hat{m}
$$

Within the context of our analytical framework, the $R^{2}$ from this regression, which we define as $R_{e}^{2}$, proxies for $V /(V+v)$ and represents the proportion of earnings variation attributable to macroeconomic factor realizations.

Next, we use $\hat{M}$ and the estimates for $B^{\prime} M$ and $m$ derived in the first regression, $\hat{B}^{\prime} \hat{M}$ and $\hat{m}$ respectively, to run a second regression to determine the extent to which forecasts contain information about the macroeconomic state:

$$
f=\hat{\mu}_{f}+\Gamma \hat{B}^{\prime} \hat{M}+\gamma \hat{m}+\eta
$$

where $\eta$ is the error term. Within the context of our analytical modeling framework, $\hat{\mu}_{f}$ is our estimate of $\mu_{f}, \Gamma$ is our estimate of $b \frac{C}{V}, \gamma$ is our estimate of $b \frac{c}{v}$, and the variance of $\eta$ is $\sigma+$ $b^{2}\left(s-\frac{C^{2}}{V}-\frac{c^{2}}{v}\right)$. Not surprisingly, the conceptual constructs reflected in the coefficients $\Gamma$ and $\gamma$, $b \frac{C}{V}$ and $b \frac{c}{v}$ respectively, reflect the nature of the manager's information, which is captured by $\frac{C}{V}$ and $\frac{c}{v}$, as well as how the manager impounds that information into his forecast, which is captured by $b$. If the manager's information can be represented as earnings plus noise and his forecast is unbiased, then $\Gamma=\gamma$.

We utilize semi-partial $R^{2}$ statistics from the regression of the form in (4) to gain some insights about the extent to which forecasts reflect macroeconomic information. ${ }^{8}$ The semi-partial $R^{2}$, or partial $R^{2}$ for short, for the macroeconomic component in regression (4), $r_{s}^{2}$, proxies for $b^{2} C^{2} / V\left(b^{2} s+\sigma\right)$ in our analytic framework and reflects the proportion of forecast variation that can be explained by the macroeconomic shock realizations. Similarly, the partial $R^{2}$ for the firmspecific component, $r_{i}^{2}$, proxies for $b^{2} c^{2} / v\left(b^{2} s+\sigma\right)$. A larger partial $R^{2}$ for a component of earnings suggests that the forecast contains more information about that earnings component.

\footnotetext{
${ }^{7}$ In the spirit of the analysis employed by Ball et al. (2009), an alternative approach to our decomposition is to employ factor analysis to identify common macroeconomic factors of earnings. Please see the Appendix for detail on the alternative implementation, which yields similar inferences.

${ }^{8} \mathrm{~A}$ convenient property of the semi-partial $R^{2}$ is that it is additive whereas the partial $R^{2}$ could lead to cases where $r_{s}^{2}+r_{i}^{2}>R^{2}$.
} 
We also attempt to determine whether, on average, the information impounded into forecasts is more or less heavily weighted towards macroeconomic factors than the earnings being forecast. For example, managers might be expected to know more about firm-specific events than macroeconomic events and that their forecasts would reflect that weighting. To ascertain whether management forecasts reflect macroeconomic news to a greater or lesser degree than the earnings itself, we compute the statistic $r_{s}^{2} / r_{i}^{2}-R_{e}^{2} /\left(1-R_{e}^{2}\right)$, which captures the forecast variation explained by the macroeconomic factor realizations relative to that explained the firm-specific shocks less the analogous ratio for earnings itself. If this value is positive (negative), it suggests that more of the information impounded into the manager's forecast is macroeconomic (firm-specific) relative to the impact of macroeconomic shocks on earnings. Within the context of our analytical framework, $r_{s}^{2} / r_{i}^{2}-R_{e}^{2} /\left(1-R_{e}^{2}\right)$ is expected to be 0 if the manager's information, $y$, can be represented as earnings plus noise, which is a theoretical specification of private information often employed in the literature.

\subsection{Extracting Information Content}

For each firm, we first run regression (3) of earnings on the macroeconomic proxies to obtain estimates of $\hat{B}$ and $\hat{m}$. Within the context of our analytical framework, the $R^{2}$ from this regression, $R_{e}^{2}$, proxies for the underlying value of $V /(V+v)$ in the analytic framework. The mean (median) $R^{2}$ is $77 \%(82 \%)$, suggesting that macroeconomic factors are significant drivers of firm earnings, which is consistent with the principal component analysis in Ball et al. (2009).

To provide a measure of the amount of macroeconomic information in individual forecasts, we run regression (4) for each firm, which is a regression of each firm's forecasts on the estimates of the firm's macroeconomic and firm-specific components of its earnings, $\hat{B}^{\prime} \hat{M}$, and $\hat{m}$ respectively. The partial $R^{2}$ for the macroeconomic component in regression (4), $r_{s}^{2}$, reflects the macroeconomic information content of the forecast and the partial $R^{2}$ for the firm-specific component, $r_{i}^{2}$, reflects the firm-specific information content. The mean (median) $r_{s}^{2}$ for these regressions is $51 \%(54 \%)$ and the mean (median) $r_{i}^{2}$ is $16 \%(10 \%)$. Hence, this evidence suggests that macroeconomic information is impounded into management forecasts in addition to firm-specific information.

Given that the events managers privately observe (e.g., sales orders) are almost surely influenced by macroeconomic factor realizations, it is hardly surprising that information regarding 
macroeconomic factor realizations is impounded into management earnings forecasts. What is less clear is whether the information underlying the manager's forecast is more weighted towards macroeconomic or firm-specific risk factors relative to what one might expect given the relative impacts of macroeconomic and firm-specific shocks on earnings. Hence, we compute the value $r_{s}^{2} / r_{i}^{2}-R_{e}^{2} /\left(1-R_{e}^{2}\right)$ which, as discussed above, is positive (negative) if more of the information in the forecasts is macroeconomic (firm-specific) relative to the impact of macroeconomic shocks on earnings. On the other hand, if the value is 0 , it suggests that the information underlying the forecast can be reflected as earnings plus noise.

A histogram of the differences between the estimates of $r_{s}^{2} / r_{i}^{2}-R_{e}^{2} /\left(1-R_{e}^{2}\right)$ for the sample is presented in Figure 1, with the tails truncated to eliminate the bottom and top $10 \%$ of values. We truncate the distribution because some of the estimates of $r_{i}^{2}$ and $1-R_{e}^{2}$ are very close to 0 , which drives extreme values in the tails. The mean (median) difference of the truncated distribution is $2.74(0.22)$ and is statistically significant at the $1 \%(10 \%)$ level. An interpretation of the statistic is that the data may suggest forecasts impound somewhat more information regarding macroeconomic shock realizations than is impounded in the underlying earnings.

\subsection{High vs. Low Macroeconomic Information}

Some firms' forecasts might naturally be expected to reflect macroeconomic shocks to a greater degree than other firms' forecasts because of the more cyclical nature of some businesses. For example, the demand for company A's product or service could be more more sensitive to the state of the macroeconomy than the demand for company B's product or service. As a consequence, a forecast from company $\mathrm{A}$, which is based in part on its advance order flows, would reflect more macroeconomic information that a forecast from company $\mathrm{B}$, which is based in part on its advance order flows. We employ a data-driven approach to measure the extent to which a company's forecast reflects macroeconomic news by using the semi-partial $R^{2}$ for the macroeconomic component in regression (4), $r_{s}^{2}$. A histogram of the values of $r_{s}^{2}$ is provided in Figure 2, which illustrates that some companies issue forecasts with more macroeconomic information content than others. The correlation between $r_{s}^{2}$ and $R_{e}^{2}$ is 0.425 and statistically significant, suggesting that firms whose earnings are impacted to a greater degree by macroeconomic shocks tend to have more macroeconomic information in their earnings forecasts. 
In our subsequent analysis, firms with an $r_{s}^{2}$ in the upper quartile are classified as high macroeconomic information content firms, or high macro firms for short, and the remainder are low macroeconomic information content firms, or low macro firms for short. Panels B and C of Table 1 provide some descriptive information for high and low macro firms. High macro firms tend to be concentrated in the manufacturing, retail, and services industries, although there is a great deal of overlap between the industries containing high and low macro firms. Furthermore, high macro firms are smaller on average than the low macro firms as measured by assets, sales, or market capitalization. The means and medians of the earnings surprise (ANALYST_SURP) and the earnings guidance surprise (CIG_SURP) are insignificantly different from 0, suggesting that the central tendency of the news conveyed by management forecasts and actual earnings is neither good nor bad.

Although we make no explicit predictions about how forecast attributes should differ by the macroeconomic information content of the forecast, management forecasts are more conservative (negative forecast errors) and accurate (lower absolute forecast error dispersion) for high macro firms. Based on untabulated results, high macro firms have a mean signed forecast error of 0.013 compared to 0.039 for low macro firms, where signed forecast error is computed as forecast minus actual. This difference is statistically significant at the $1 \%$ level. High macro firms have a mean absolute forecast error of 0.047 compared to 0.099 for low macro firms. This difference is also statistically significant at the $1 \%$ level. To determine whether these relationships explain our primary findings, we conduct supplementary analysis related to forecast characteristics later in the paper.

\section{Management Forecast Timeliness}

If disclosure influences the cost of capital by informing market participants about macroeconomic risk factor realizations, it should provide timely (i.e., new) information to the market regarding those realizations. While the descriptive analysis above suggests that management forecasts contain information about the macroeconomic state, it provides little evidence that the information is timely. Our primary tests of timeliness are short-window event study tests using equity market data. In those tests, we examine how market portfolio returns are associated with surprises in 
management forecasts during the forecast announcement window. In addition to first moments (i.e., means) of beliefs, we examine second moments (i.e., variances), given that forecast surprises may convey such information.

Although short window tests of the form we construct can provide reasonably compelling evidence regarding timeliness, we acknowledge that these tests provide less compelling evidence of causality. Because of the sheer daily volume of disclosures by news organizations, business commentators, executives, and governmental officials, we attempt to address concurrent disclosure issues in supplemental analysis.

\subsection{Equity Market Tests}

We conduct short-window regression analyses to test for an association between an individual firm's forecast surprise and the market portfolio return, excluding the return of the forecasting firm, around the release of the forecast. Approximately $80 \%$ of the forecasts in our sample are bundled with earnings. Because bundled forecasts are more likely to arise as a matter of predictable firm policy whereas unbundled forecasts are more likely to arise as a matter of information arrival, the average responses to the two types of forecasts are likely to differ. Furthermore, in the case of bundled forecasts, we must control for the coincident earnings release whereas there is no such release to control for with an unbundled forecast. For these two reasons, we run separate regression analyses for the bundled and unbundled forecasts. For the bundled forecasts, we estimate the following regression:

$$
\begin{aligned}
C R_{i, t} & =\alpha+\beta_{1} C_{I} G_{-} S U R P_{i, t}+\beta_{2} A N A L Y S T_{-} S U R P_{i, t}+\beta_{3} B O N D_{t-1}+\beta_{4} C P I_{t-1} \\
& +\beta_{5} H_{\text {OUS SING }}+\beta_{6} I_{t-1} D P R O D_{t-1}+\beta_{7} R G D P_{t-1}+\beta_{8} T B I L L_{t-1} \\
& +\beta_{9} \text { TBOND } D_{t-1}+\beta_{10} U N E M P_{t-1}+\varepsilon_{i, t}
\end{aligned}
$$

where $\mathrm{CR}_{i, t}$ is the cumulative value-weighted market return excluding firm $i$ over the $t$ days surrounding the release of the management forecast, CIG_SURP ${ }_{i, t}$ equals the actual guidance given by management (CIG_ACTUAL) less the estimated consensus analyst forecast, and ANALYST_SURP $_{i, t}$, is the realized earnings (EARN_ACTUAL) less the most recent analyst consensus 
prior to the announcement date scaled by beginning of quarter price. ${ }^{9}$ We incorporate macroeconomic time series (MTS) forecasts provided by the Federal Reserve Bank (FRB) of Philadelphia prior to the management forecasts in order to control for an aggregate return risk premium (Cready and Gurun, 2010). For the unbundled forecasts we run the same regression excluding the ANALYST_SURP $_{i, t}$ variable.

Value-weighted returns are employed in regression (5) because we believe value-weighted returns are more reflective of the aggregate macroeconomic state due to the fact that larger firms naturally comprise a greater portion of the total macroeconomy. Similar results, however, are obtained when we use equal-weighted returns.

Because of coincident information events (i.e., other management earnings forecasts released in the same time horizon), overlapping windows present a challenge for our analysis. During our sample period, on days when at least one firm provides earnings guidance, the mean (median) number of firms providing earnings guidance on that day is 9.58 (5.00). Thus, as a consequence, $\varepsilon_{i, t}$ in regression (5) will be correlated across observations. To mitigate the problem of this dependence in the error term, we cluster regression standard errors by firm and forecast announcement quarter. In supplemental tests, we also cluster standard errors by forecast month, week, and day and obtain similar results. Because of the coincidence of forecasts, in supplemental analysis, we examine the sensitivity of our primary results to: (1) the inclusion of overlapping forecasting firms' returns in the market portfolio, and (2) forecasts made during earnings guidance "seasons" during which many firms provide earnings forecasts in a concentrated period of time.

We predict the coefficient on CIG_SURP ${ }_{i, t}$ to be positive if forecasts contain timely information about macroeconomic risks. Inherent to our test is an additional hypothesis that firms are predominantly pro-cyclical. If, say, half of the firms are counter-cyclical (i.e., $\beta_{1}<0$ ) and half are pro-cyclical $\left(\beta_{1}>0\right)$, our test is misspecified and would likely suggest that the forecasts do not contain timely macroeconomic information content. Our prior beliefs regarding the predominance of pro-cyclical firms is driven by market return findings in Anilowski et al. (2007) regarding qualitative management forecasts as well as the intra-industry findings in Baginski (1987) regarding management forecasts.

We run regression (5) over three return windows: a three-day window $(-1,+1)$, a five-day window

\footnotetext{
${ }^{9}$ We also use total assets as an alternative scalar and find similar results.
} 
$(-1,+3)$, and a twelve-day window $(-1,+10)$. Given our interest in the timeliness of forecasts, we place our emphasis on the shortest window and employ multiple windows to corroborate our findings in the shortest window. Table 2 provides the results from regressions of the form in equation (5). Consistent with our expectations, we find a statistically significant positive relation between bundled earnings guidance news, CIG_SURP, and aggregate equity market returns for all return windows $(-1$ to $+1,-1$ to $+3,-1$ to +10$)$ surrounding the guidance release. The coefficients of 0.796, 1.546, and 3.470 imply, on average, that aggregate market returns increase by $0.02 \%, 0.04 \%$, and $0.09 \%$, respectively, as the news in firms' management forecasts increases by one standard deviation. ${ }^{10}$ Although small in magnitude compared with response coefficients from firm-specific studies, our results appear to be economically meaningful in the context of an individual firm's influence on the broader equity market.

While the results in Table 2 suggest that earnings guidance in bundled forecasts provide timely information to the broader stock market, we find little evidence that unbundled guidance provides similar timely macroeconomic information, which is consistent with unbundled guidance being driven by more idiosyncratic negative shocks to individual firms. In Table 2, only the coefficient on CIG_SURP for the $(-1,+1)$ window is statistically significant at conventional levels, and it is only at the 0.10 level. One possible explanation for the weak results for unbundled forecasts is that these forecast surprises are attributable to one-time events that are primarily firm specific in nature and, as a consequence, have little macroeconomic news whereas routine bundled forecasts tend to reflect underlying cyclical macroeconomic events. Consistent with this conjecture, we find that the $r_{s}^{2}\left(r_{i}^{2}\right)$ from regression (4) is statistically higher (lower) for bundled forecasts compared to unbundled forecasts. The values of $r_{s}^{s}\left(r_{i}^{2}\right)$ for bundled and unbundled forecasts are 0.505 and 0.487 (0.175 and 0.189) respectively. We generally find no statistically significant evidence related to unbundled forecasts in any subsequent analyses, and therefore restrict our analysis to bundled forecasts for the remainder of the paper.

It should be noted that the coefficients on the earnings surprise, ANALYST_SURP $i, t$, in the

\footnotetext{
${ }^{10}$ Table 2 reveals an increase in the magnitude of our estimated coefficient on CIG_SURP as our estimation window lengthens from $(-1,+1)$ to $(-1,+10)$, which could be consistent with the results found by Cohen and Frazzini (2008) that indicate it takes some time for the market to impound news about related firms. While we employed multiple announcement windows for the sake of corroborating our base results, the apparent increase in the magnitude of the market reaction to earnings guidance news is unexpected. However, as noted later in the paper, the pattern of increasing coefficients observed in the base sample disappears in the out-of-sample analysis.
} 
regressions involving bundled forecasts exhibit no consistent statistically significant relation, which is also the case in some subsequent analysis as well. Thus, firm-level earnings surprise does not appear to convey timely information about macroeconomic news. As discussed by Rogers and Van Buskirk (2012), however, the observation that earnings exhibits no statistically significant relation with returns should not be interpreted as implying that the earnings surprise would also appear incrementally uninformative if no guidance were provided, nor should the coefficient on the earnings guidance surprise, CIG_SURP ${ }_{i, t}$, be interpreted as capturing the incremental information content of the forecast over and above the earnings. Since the management forecast may incorporate the concurrently released earnings surprise, the forecast surprise could subsume the earnings surprise as long as the forecast also contains information over and above earnings.

Regardless of Rogers and Van Buskirk's (2012) observation, the forecast surprise in regression (5) would not load if the forecast did not contain macroeconomic information beyond that contained in earnings. Hence, the test is still a valid assessment of whether the forecast contains timely macroeconomic information. The coefficients, however, must be carefully interpreted (i.e., conditioned on observing both the forecast and earnings). In supplemental analysis, we employ the procedure proposed by Rogers and Van Buskirk (2012) in an effort to isolate the incremental information content of the forecast beyond that in the concurrent earnings release.

\subsubsection{Bellwether Firms}

If a manager's forecast conveys a large amount of macroeconomic information and is timely, the manager's firm is likely to be viewed as a bellwether firm because the manager's forecast has significant timely information regarding the future performance of other firms. We have empirically identified firms with more macroeconomic information in their forecasts, high macro firms, and we expect these firms' forecasts to be as timely as other firms' forecasts. Accordingly, we expect high macro firms to be bellwether firms and, as a consequence, anticipate that their forecasts will have a greater association with market returns around the forecast announcement date. To assess whether 
high macro firms are bellwether firms, we run stacked regressions of the form:

$$
\begin{aligned}
C R_{i, t} & =H I_{-} M A C R O_{I N D=1}\left(\alpha+\beta_{1} C I G_{-} S U R P_{i, t}+\sum \gamma C O N T R O L S+\varepsilon_{i, t}\right) \\
& +H I_{-} M A C R O_{I N D=0}\left(\alpha+\beta_{1} C I G_{-} S U R P_{i, t}+\sum \gamma C O N T R O L S+\varepsilon_{i, t}\right)
\end{aligned}
$$

where HI_MACRO $I N D=1$ is an indicator variable that takes on the value of 1 if firm $i$ has a partial $R^{2}$ associated with macroeconomic shocks in the upper quartile of $r_{s}^{2}$ from regression (4) and is 0 otherwise, HI_MACRO $I N D=0$ is an indicator variable that takes on the value of 1 if firm $i$ has a partial $R^{2}$ associated with macroeconomic shocks in the lower three quartiles of $r_{s}^{2}$ and is 0 otherwise, and CONTROLS refers to all the control variables employed in regression (6). If bellwether firms are defined by the macroeconomic information in their forecasts, we expect $\beta_{1}>0$ where HI_MACRO $I N D=1$. Further, if high macro firm forecasts convey more macroeconomic information, we expect $\beta_{1}$ to be greater when HI_MACRO ${ }_{I N D=1}$ than when HI_MACRO IND=0.

Table 3 presents results of regression (6). Consistent with our expectations, $\beta_{1}$ is statistically significant at the $1 \%$ level for all return windows $(-1$ to $+1,-1$ to $+3,-1$ to +10$)$ where HI_MACRO ${ }_{I N D=1}$. The coefficients of $1.477,2.488$, and 5.045 imply, on average, that aggregate market returns increase by $0.04 \%, 0.07 \%$, and $0.14 \%$, respectively, as the news in firms' management forecasts increases by one standard deviation. F-tests reveal that the differences between $\beta_{1}$ where HI_MACRO $I N D=1$ and HI_MACRO ${ }_{I N D=0}$ are statistically significant at the $5 \%$ level for the -1 to +1 return window, and $10 \%$ level for the longer windows, which is consistent with our prediction that high macro firms are bellwether firms. In fact, $\beta_{1}$ is never statistically different from zero in Table 3 for any of the return windows where HI_MACRO IND=0. Thus, bundled earnings forecasts appear to convey significant timely information about macroeconomic news only for firms whose forecasts have a greater association with macroeconomic factors.

As also shown in Table 2, the coefficient on ANALYST_SURP in the Table 3 regressions is generally statistically insignificant. However, in the $(-1,+10)$ window, the coefficient on ANALYST_SURP is 2.274 for high macro firms, which is statistically significant at the $1 \%$ level. This result is consistent with firm-level earnings surprise conveying some timely information about aggregate cash flow news, based on the positive coefficient. 


\subsubsection{Proximity}

We have established that high macro firms' forecasts have timely macroeconomic information content. The exact nature of the macroeconomic information content in those forecasts could be due to either the forecast reflecting broad economy-wide news pertaining to the performance of almost all firms or, alternatively, narrower industry specific news pertaining to the performance of a measurable set of firms in the market portfolio, which would still make it an undiversifiable news event. As an illustrative example, assume an economy with two industries, A and B, where A relies heavily on an imported commodity product as an input and B does not. If there is a supply disruption for the commodity due to, say, a simmering regional conflict, industry A is adversely affected and the equity prices of industry A firms decline when there is news signalling the supply chain disruption. If the economy is sufficiently "closed," then B may be adversely affected as well because consumers whose income is adversely affected by the shock to A will not demand as much of B's product. In this case, then, news about the supply chain disruption would be associated with declines in the equity prices of firms in both A and B. Within the context of the analytic framework, this scenario would imply the relevant coefficient in the vector $B$ would be nonzero and of the same sign for firms in both industries. Alternatively, if the economy is sufficiently "open" so the demand for industry B's product is unaffected by the shock to A's supply chain, then B's equity price would not be affected by the shock to industry A's supply chain. Within the context of the analytic framework, the relevant coefficient in vector $B$ would be 0 for firms in industry B.

To determine whether the macroeconomic information captured in the forecasts of high macro firms reflects broad economy-wide or narrower industry-specific news, we run stacked regressions of the form in equation (3) for firms in the same four-digit SIC as the forecasting firm and those outside of the forecasting firm's SIC division. The results of these regressions are presented in Table 4. Across all three return windows, management forecasts have a statistically significant association with the aggregate returns of firms inside the forecasting firm's four-digit SIC and outside its SIC division category. The returns of firms within the same 4-digit SIC increase, on average, by approximately $0.14 \%, 0.22 \%$, and $0.39 \%$ per standard deviation increase in CIG_SURP across our three announcement windows. For firms outside the SIC division of a forecasting firm, the announcement period returns average $0.03 \%, 0.05 \%$, and $0.11 \%$ per standard deviation increase 
in CIG_SURP respectively. Thus, the forecasts contain information regarding both industry-wide and economy-wide news. Further, the magnitude of the reaction is larger for firms within the same four-digit SIC, suggesting that the information regarding industry-wide news is greater than that related to economy-wide news. F-tests of the differences in the coefficients on CIG_SURP between the two industry groupings are statistically different at $1 \%$ level for the $(-1,+1)$ and $(-1,+3)$ windows and at the $5 \%$ level for the $(-1,+10)$ window.

With respect to our earnings surprise variable, ANALYST_SURP, we find some evidence that industry portfolio returns react positively to firm-level earnings news with coefficients of 1.377 , 3.831 , and $6.782(1.567,3.887$, and 6.757) for the regressions without (with) macroeconomic time series controls, all statistically significant at the $10 \%$ level or better. Accordingly, the result only found in the $(-1,+10)$ window in Table 3 appears in all three Table 4 return windows for the within industry portfolio returns, suggesting that the "aggregate" cash flow news found in firmlevel earnings surprises relates to industry cash flows news rather than overall market cash flows news, which is consistent with the findings of Choi et al. (2012). Finally, although we find some evidence that firm-level earnings news provides timely information about industry cash flows, the magnitude of the market return association is only a fraction of that in relation to the management forecast surprise. In the $(-1,+1)$ window, the industry portfolio association is almost four times as much for a particular unit of forecast surprise as it does for the same unit of earnings surprise. For the other two return windows, the market return association with guidance surprise is more than twice as large as the return association with earnings surprise. Consistent with recent firm-level evidence (Ball and Shivakumar (2008), Beyer et al. (2010), and Milian (2010)), guidance surprise appears to convey more information to broader equity prices than earnings surprise.

\subsubsection{Forecast Attributes}

Prior research has shown that a forecasting firm's stock price response is larger when the forecast news is bad and when the forecast range is narrower. ${ }^{11}$ A rationale offered for the former finding pertaining to the direction of the forecast news is that litigation and reputation concerns induce

\footnotetext{
${ }^{11}$ See Hutton et al. (2003), Skinner (1994), and Soffer et al. (2000) for examples documenting the asymmetric stock market response to good news and bad news management earnings forecasts. Also, see Baginski et al. (1993) and Pownall et al. (1993) for examples of studies documenting stronger stock market reactions to point versus range management earnings forecasts.
} 
firm management to reveal bad news in a more timely manner than good news. Hence, good news forecasts are relatively less timely on average and, accordingly, are associated with a smaller stock price response during the forecast announcement window. We do not expect the litigation incentives to be strongly associated with the macroeconomic content of forecasts because firm management can be sued only by those with direct claims on the firm and those potential plaintiffs' claims would not be tied to the macroeconomic content of the news. We therefore expect bad news forecasts to provide more timely revelations of firms' macroeconomic news relative to equivalent good news forecasts.

The rationale for the second finding pertaining to the forecast range is that management uses the forecast range to signal the precision of information underlying the forecast. The rationale refers to precision regarding the earnings realization as opposed to precision regarding the macroeconomic component of earnings. We anticipate, however, that a more precise signal of earnings is a more precise signal of both of its components. Consequently, we expect that high macro forecasts involving a narrower forecast range will be associated with a larger market response.

To test the two conjectures regarding the attributes of the forecast and the equity market response, we run two regressions of the form:

$$
\begin{aligned}
C R_{i, t} & =\operatorname{ATTR}_{I N D=1}\left(\alpha+\beta_{1} C I G_{-} S U R P_{i, t}+\sum \gamma C O N T R O L S+\varepsilon_{i, t}\right) \\
& +\operatorname{ATTR}_{I N D=0}\left(\alpha+\beta_{1} C I G_{-} S U R P_{i, t}+\sum \gamma C O N T R O L S+\varepsilon_{i, t}\right)
\end{aligned}
$$

where $A T T R \in\left\{P O S_{-} S U R P, P O I N T\right\}$ and POS_SURP is a binary variable set equal to one if a firm's earnings guidance exceeds analysts' consensus estimate immediately prior to the guidance release and zero otherwise and POINT is a binary variable set equal to one if a firm's earnings guidance is a point estimate and zero if it is a range. If our conjectures are correct, we expect the coefficients on CIG_SURP for bad news and point forecasts to be more positive than the corresponding coefficients for good news and range forecasts.

We present our estimation of regression (7) for each attribute type in Table 5. As shown in Panel A, consistent with our expectations for aggregate stock returns and with prior studies on firm-specific equity market reactions to earnings guidance, we document a more pronounced relation between the market return and the guidance for bad news. For a one standard deviation increase 
in guidance news, we estimate that the aggregate equity market responds by $0.75 \%$ more for bad news forecasts than good news forecasts in the $(-1,+1)$ window around guidance releases. In the $(-1,+3)$ window around guidance releases, this difference is approximately $1.36 \%$ on average. For both windows, F-tests of the difference in CIG_SURP across good and bad news partitions are statistically significant at the $5 \%$ level for the $(-1,+1)$ and $(-1,+3)$ windows. We do not, however, find a statistically significant difference across the partition for the $(-1,+10)$ window. Overall, the evidence in Panel A of Table 5 is consistent with prior firm-specific research and our expectations regarding macroeconomic information content insofar as bad news guidance is more timely and/or credible than good news guidance for high macro firms.

Turning to Panel B of Table 5, we present our results for the estimation of regression (7) related to point versus range earnings guidance. Again, consistent with prior research and our expectations, we find a more pronounced aggregate stock market response to point compared to range forecasts. In our primary announcement period window of $(-1,+1)$, a one standard deviation increase in guidance news is associated with $0.86 \%$ higher aggregate stock return for point forecasters compared with range forecasters. An F-test of the difference in coefficients on CIG_SURP between the point and range partitions is statistically significant at the $10 \%$ level. Our other announcement period windows of $(-1,+3)$ and $(-1,+10)$ reveal similar inferences with $1.14 \%$ and $2.39 \%$ higher aggregate stock returns per one standard deviation of guidance news respectively. These differences across the partitions are also statistically different at the $10 \%$ and $5 \%$ levels, respectively, based on the F-tests found in Table 5. Again, consistent with prior firm-specific research and our expectations regarding macroeconomic information content, the results in Panel B of Table 5 suggest that more precise point forecasts are associated with greater stock price movements than range forecasts.

\subsection{Market Volatility}

Research on "volatility feedback" (Black, 1976; Christie, 1982; Campbell and Hentschel, 1992; French et al., 1987; Wu, 2001) shows that overall stock market volatility is generally higher after stock prices fall than after they rise. If the movements in stock prices are associated with the disclosures released to the market, then this empirical observation suggests bad news might be associated with increases in volatility and good news associated with decreases in volatility. Consistent with this reasoning, Kim et al. (2012) find that market wide volatility is negatively associated with prior 
aggregate guidance provided to the market and Rogers et al. (2009) show that implied volatilities derived from traded option prices for a given firm are negatively associated with news conveyed by management forecasts for that firm.

If individual firms' earnings guidance conveys macroeconomic information, a similar relation between market-wide volatility and individual firm guidance is plausible for two reasons. First, poor performance at the macroeconomic level implies that, on average, firms become more levered, which makes the future cash flows for equity claims more sensitive to future performance. As a consequence of this leverage effect on the uncertainty of cash flows accruing to equity holders, future stock price volatility increases when current performance is poor because equity prices become more sensitive to future reported performance (Black, 1976; Christie, 1982; Campbell and Hentschel, 1992; French et al., 1987; Wu, 2001). If, therefore, individual firm forecasts contain timely macroeconomic news pertaining to the performance of many or all firms, we expect that news to be associated with changes in market wide volatility due to the leverage effect.

Second, the direction of the macroeconomic news in an earnings forecast could also convey information regarding the volatility of underlying macroeconomic fundamentals. ${ }^{12}$ In particular, greater (lower) fundamental volatility could naturally cause individuals to be more cautious (assertive) in their investing and consumption activities, which implies lower (greater) earnings and, hence, earnings forecasts. As a consequence, the earnings forecasts would convey information about the evolution of the volatility of macroeconomic fundamentals. If fundamental volatility is associated with equity price volatility, then we expect a relation between individual firm forecast news and equity price volatility.

We test this conjectured link between individual firm forecasts and market wide volatility by assessing whether the news in management forecasts is associated with changes in the Chicago Board Options Exchange Volatility Index (VIX) during short announcement period windows. ${ }^{13}$ In

\footnotetext{
${ }^{12}$ In studying the relation between economic policy uncertainty and future economic fluctuations, Baker et al. (2012) find that increases in their constructed index of policy-related economic uncertainty foreshadow declines in real GDP, private investment, and aggregate employment.

${ }^{13} \mathrm{Kim}$ et al. (2012) use the VIX to examine the association between overall market uncertainty and both the decision to issue management earnings guidance and the characteristics of earnings guidance.
} 
particular, we run regressions of the following form:

$$
\begin{aligned}
\Delta V I X_{-t,+t} & =P O S_{-} S U R P_{I N D=1}\left(\alpha+\beta_{1} C I G_{-} S U R P_{i, t}+\sum \gamma C O N T R O L S+\varepsilon_{i, t}\right) \\
& +P O S \_S U R P_{I N D=1}\left(\alpha+\beta_{1} C I G_{-} S U R P_{i, t}+\sum \gamma C O N T R O L S+\varepsilon_{i, t}\right)
\end{aligned}
$$

where $\Delta V I X_{-t,+t}$ is the change in the VIX in the $t$ days surrounding the forecast announcement and POS_SURP is 1 if the guidance surprise is positive and 0 otherwise. We have allowed the relation to be asymmetric because of the likelihood that bad news forecasts are more timely than good news forecasts, which would suggest that the association within the forecast event window will be more pronounced for bad news.

The results of our estimation of regression (8) can be found in Table 6. As documented in Table 6, there is evidence of a negative association between CIG_SURP and changes in VIX for both good news and bad news forecasts; although the former is more statistically significant, the latter is more economically significant. For the $(-1,0)$ window, only good news guidance appears to have a statistically significant effect on the VIX $\left(\beta_{1}=-1.485\right.$; significant at the $1 \%$ level without macroeconomic time series controls and $\beta_{1}=-1.174$; significant at the $1 \%$ level with macroeconomic time series controls), but for the $(-1,+1)$ window both bad new and good news forecasts exhibit a statistically significant association with changes in the VIX. For good news guidance, $\beta_{1}$ is statistically significant at the $1 \%$ level, while for bad news guidance, $\beta_{1}$ is significant at the $10 \%$ level. We conduct F-tests of the differences between $\beta_{1}$ for bad news guidance and good news guidance. Focusing on the results for regressions with macroeconomic time series controls, our results imply a 2.54 basis point decrease in the VIX for every one standard deviation increase in guidance surprise for good news guidance and 116.12 basis point increase in the VIX for every one standard deviation decrease in guidance surprise for bad new guidance. Thus, guidance news for bad news forecasts is associated with fairly economically significant change in the market's perceptions of future volatility.

Finally, note that the relation between guidance news and changes in volatility dovetail nicely with the relation between guidance news and equity market returns. Because macroeconomic uncertainty is priced, greater uncertainty should be associated with price declines and vice versa. Because the guidance news is negatively related to market uncertainty, we would expect market 
returns to be positively related to guidance news.

\section{Supplemental Tests}

Our last set of analyses consists of supplemental tests to shed light on whether our findings have been substantially influenced by disclosure bunching, misspecification of the forecast surprise for bundled forecasts, or our particular approach for measuring the macroeconomic information content in firms' forecasts. In addition, we consider whether controlling for two firm attributes, size and forecast accuracy and pessimism, alter the empirical relations identified previously in the paper. Finally, we assess whether our results are attributable to forecasts during particular time periods.

\subsection{Disclosure Bunching}

As discussed earlier, individual forecasts are not the only disclosures occurring during a forecast announcement window and the associations we document could arise from a forecast having news that is correlated with the news in other concurrent disclosures. Since we cannot rule out this possibility, we conduct some supplemental analysis to assess whether it is a primary driver of the associations we document.

\subsubsection{Forecast Bunching}

For the vast majority of our forecasts, there are multiple coincident forecasts occurring on the same date. We have used two-dimensional clustered standard errors in our regressions by firm and quarter to address the issue of correlated error terms. Because a quarter might not be the relevant time dimension upon which to cluster, however, we also re-estimate our primary regressions (5) and (6) to assess whether clustering by day, week, or month alters our insights. Regardless of which time dimension is used for clustering, we obtain similar findings.

While clustering can alleviate the issue of correlated errors, it may still be the case that bunches of forecasts occurring in any return window could be a driver of our results. For example, if enough firms forecast in the same return window, there is some possibility our results could arise because of correlation in those forecasts. In other words, the market response arises because of coincident forecasts as opposed to broad spillovers, which is the premise of the argument made by Anilowski 
et al. (2007) who argue that the pervasiveness of earnings guidance should make it more informative to the market as a whole. We take two approaches to assess whether our results in Table 3 may be attributable to forecast bunching.

First, we re-run our primary regressions, but exclude the returns of all firms providing earnings guidance from the market portfolio in any given return window from the computation of $C R_{i t}$. During the time period covered by our sample, in any given 12-day period (the length of time covered by our $(-1,+10)$ announcement period window), there are a maximum of 411 firms providing forecasts. This number represents approximately $5.9 \%$ of the average 6,932 firms included in the market portfolio per CRSP. However, the mean (median) number of unique forecasts in any given 12day span is significantly lower at 99 (60), which represents approximately $1.4 \%(0.9 \%)$ of the average number of firms included in the market portfolio. Thus, we do not expect the removal of coincident forecasters' returns from the market portfolio return to materially affect our inferences. Consistent with these expectations, the coefficients on CIG_SURP in these regressions using this modified estimate of the aggregate market return exhibit the same magnitudes and levels of statistical significance as found in Table 3, which suggests that the associations we document are not solely driven by correlations in the returns of coincident guidance providers.

Second, we assess whether our results are driven solely by forecasts occurring during periods of intense forecast bunching (i.e., periods of time when there are many concurrent forecasts), which could occur if each individual forecast in an announcement window is correlated with the others in that same window and each has small spillover effects to a few other firms in the market. In particular, under these conditions, we could find an association between an individual forecast and the market return even if concurrent forecasts are eliminated from $C R_{i t}$ because of the small spillover effects associated with many concurrent forecasts. Within our sample, forecast frequencies vary substantially throughout the year, with the most dense periods of forecast bunching occurring at the end of January, April, July, and October. Given that observation, we re-estimate our primary regressions for forecasts made outside the last ten days of these months ("non-season" forecasts) and those made within the last ten days of January, April, July, and October ("season" forecasts).

In Table 7, we provide the results of re-estimating equation (6), which underlies Table 3, for our two data partitions. The coefficients on CIG_SURP for each of the three announcement period windows in the "non-season" partition are 1.168, 1.986, and 3.816, which are all slightly smaller 
in economic magnitude than those found in Table 3, although statistical significance is achieved at the $5 \%$ level or better for each window. In addition, F-tests reveal that the coefficients on CIG_SURP for forecasts made during forecasting "seasons" are statistically larger than those for forecasts made during forecasting "non-seasons" for the $(-1,+1)$ and $(-1,+3)$ windows, suggesting that bunched forecasts likely partially contribute to our primary findings in Table 3 . However, the significance of the CIG_SURP coefficients in the "non-season" sub-sample imply that our primary results are not attributable solely to periods of intense forecast bunching.

\subsubsection{Return Window Width}

In addition to bunching with other forecasts, earnings guidance is not necessarily released to the market independent of other macro-relevant news events. On any given day, there are a range of economic variables that governmental agencies release including: GDP, inflation, unemployment, crude inventories, home sales, factory order, and consumer confidence, just to name a few. In order to alleviate some concerns regarding coincident events, we re-estimate our regressions using a return window of one day, the guidance announcement date. ${ }^{14}$ The one-day window results corroborate our primary findings and reduce the likelihood that coincident events drive the multi-day window results presented in our primary analysis. For example, the estimations that include macroeconomic time series control variables yield a coefficient on CIG_SURP that is 1.402 (statistically significant at the $1 \%$ level) for high macro firms and 0.0379 (statistically insignificant at the $10 \%$ level or better) for low macro firms. The difference of 1.3641 is statistically significant at the $5 \%$ level. The coefficient of 1.402 is only $5.1 \%$ less than the comparable coefficient for the $(-1,+1)$ window, which suggests that the results in a tighter event window are reflecting similar news.

\subsection{Measuring Forecast Surprise}

Rogers and Van Buskirk (2012) show that the standard measure of forecast surprise may misspecify the incremental information content of the forecast if the forecast is bundled together with an earnings announcement. Their assertion is based upon the observation that the analyst forecast used to compute $C I G_{-} S U R P_{i, t}$ does not incorporate the new information contained in the earnings realization bundled with the forecast. Consequently, Rogers and Van Buskirk (2012) devise an

\footnotetext{
${ }^{14}$ We use the trading day following the guidance announcement if the announcement occurs after trading hours.
} 
approach for estimating the conditional consensus forecast and associated forecast surprise. We re-estimate our primary regressions using the alternative forecast surprise measure and find that the estimated coefficients are similar, though slightly dampened.

\subsection{Measuring Macroeconomic Information Content}

Our approach for identifying the macroeconomic information content of forecasts has relied upon an in-sample, data-intensive methodology, suggesting a possibility of significant hindsight and overfitting in identifying firms high macro firms. Both of these observations merit some supplementary analysis to assess whether a methodology not involving hindsight or a simpler methodology might do as well in identifying firms with higher macroeconomic content forecasts. In addition, we examine whether our results are sensitive to how we partition firms into high and low macro categories based on the estimation of regression (4).

\subsubsection{Hindsight}

The hindsight issue is of concern from an implementation perspective because researchers and analysts generally do not have the benefit of hindsight for identifying which firm forecasts have higher macroeconomic information content. Furthermore, one might attribute the drift (larger coefficients for longer return windows) observed in our earlier analysis of high macro firm forecasts as being attributable to hindsight bias. To see why, consider a world in which market participants do not know exactly which firms have the most macroeconomic information. As a consequence, aggregate market prices respond in part to all firm disclosures because market participants know, on average, that some have macroeconomic content. In turn, the market under-reacts to the truly high macro forecasts and prices exhibit drift in the direction of truly high macro forecasts. This line of reasoning also implies that prices should overreact to those disclosures with low macroeconomic content and that reversals should be observed for such disclosures. While we have observed some evidence of the drift associated with high macro firm forecasts, we have not observed evidence of reversals associated with low macro firm forecasts. If the initial reactions are small enough and high macro firms are rare, however, the initial reactions and subsequent reversals might be difficult to detect in the data.

In order to address the hindsight issue, we first employ a rolling approach, which involves re- 
estimating regression (4) using varying lagged forecast windows for estimation of the $r_{s}^{2}$ statistic used to categorize the level of macroeconomic information content. In our base analysis, we use all available forecast observations for a particular firm to estimate macroeconomic information content. As part of our rolling approach, we limit the number of lagged quarters per firm (i.e., 15, 20, 25, 30) and compare our estimated partial $r_{s}^{2}$ statistic to that obtained from the base analysis. Using that approach, we find that firms with a high macro designation in our base analysis have roughly a $90 \%$ likelihood of having the high macro designation in our various rolling approach iterations. This observation suggests that macroeconomic information content is fairly sticky across time, which implies that hindsight does not play a significant role in identifying high macro firms.

Next, we re-estimate regression (6) using out-of-sample guidance from the period 2009 - 2011 and high/low macro designations from the period 2000 - 2008. Hence, this out-of-sample test does not involve hindsight in identifying high and low macroeconomic content firms. The results of our out-of-sample estimation of regression (6) corroborate our primary analysis in documenting a statistically significant positive association between announcement period aggregate stock returns and firm-level earnings guidance news only for high macro firms, albeit the levels of significance are somwhat weaker. Further, the pattern of increasing coefficients observed in the base sample, which is consistent with some notion of drift, disappears in the out-of-sample analysis, which is consistent with hindsight giving rise to the drift observed in our earlier results.

\subsubsection{Single Factor Approach}

We also consider a simpler, single factor approach for identifying high macroeconomic information content firms to ascertain whether the identification of high macro firms could be done with less data. For each firm's forecast, we estimate an earnings beta by regressing a firm's lagged series of earnings on a value-weighted index of earnings from all Compustat firms for the corresponding quarters. Analogous to the approach used by Hann et al. (2012), we use the estimated coefficient on the value-weighted index earnings as an estimate of firms' sensitivities to macroeconomic information, we categorize firms as high macro if their earnings beta falls in the highest sample quartile $(E B E T A)$. Next, we re-estimate our various market response tests and compare them to those estimated using our multi-factor approach.

The single factor approach generally yields results consistent with our base analysis albeit 
with somewhat diminished statistical significance, suggesting a single-factor approach is effective at identifying firms with high macroeconomic content forecasts. When we include both the single factor proxy alongside the multi-factor proxy for high macroeconomic information content in a single regression, however, the latter proxy subsumes the former as the single factor proxy loses all statistical significance.

\subsubsection{Alternative Quantiles}

We consider a firm to possess high macroeconomic information content if the firm has a partial $R^{2}$ associated with macroeconomic state variables in the upper quartile of $r_{s}^{2}$ from regression (4). Because the bivariate partition of the data into "high macro" and "low macro" is very coarse, we constructed finer partitions of the data to ascertain whether the pattern established in the coarse partition extends to finer partitions. To do this, we re-run our primary analysis using several different quantiles (terciles, quintiles, deciles, and vigintiles) and find that statistically significant results tend to cluster at the upper end of the distribution and statistically insignificant results in the remainder of the distribution. For example, when we consider whether there is a statistically significant relation between the forecast surprise and market returns for either the first, second, or third quartiles individually, we find that none exists.

\subsection{Other Firm Attributes}

\subsubsection{Size and Market Response to Management Forecasts}

Anilowski et al. (2007) provide evidence that qualitative forecasts made by larger firms have broader spillover effects than forecasts by smaller firms, which suggests that larger firms are bellwether firms. Given our analytical framework, one reason why larger firms may serve as bellwether firms is that their forecasts contain more macroeconomic information than other firms. In other words, size is a proxy for macroeconomic content. However, the fact that high macro firms are smaller than other firms in our sample, and that our proxy for size (market capitalization) is imperfectly correlated with our measure of macroeconomic content $(\rho=-0.074$, which is statistically significant at the $1 \%$ level), suggests that size is a different proxy than our measure macroeconomic content. Hence, it is unclear whether size is a complement to or a substitute for our measure and, if it is the latter, 
it is unclear whether the macroeconomic content captured in our metric subsumes or is subsumed by size.

To attempt to ascertain the role size might play in explaining market-wide spillover effects over and above the macroeconomic information proxy we employ, we run the following stacked regression:

$$
\begin{aligned}
C R_{i, t} & =H I_{-} M A C R O_{I N D=1}\left(\alpha+\beta_{1} C I G_{-} S U R P_{i, t}+\beta_{2} S I Z E_{-} I N D_{i, t}\right. \\
& \left.+\beta_{3} C I G_{-} S U R P_{i, t} * S I Z E_{-} I N D_{i, t}+\sum \gamma C O N T R O L S+\varepsilon_{i, t}\right) \\
& +H I \_M A C R O_{I N D=0}\left(\alpha+\beta_{1} C I G_{-} S U R P_{i, t}+\beta_{2} S I Z E_{-} I N D_{i, t}\right. \\
& \left.+\beta_{3} C I G_{-} S U R P_{i, t} * S I Z E_{-} I N D_{i, t}+\sum \gamma \text { CONTROLS }+\varepsilon_{i, t}\right)
\end{aligned}
$$

where $S I Z E_{I} I N D$ equals 1 if the firm is in the highest sample quartile of market capitalization. If $S I Z E_{-} I N D$ reflects bellwether firms beyond what is captured by our proxy for high macroeconomic information content, we expect $\beta_{3}>0$. Again, $\beta_{1}$ continues to load in the predicted direction where $H I_{-} M A C R O_{I N D}=1$ and is statistically greater than where $H I_{-} M A C R O_{I N D}=0$, which is statistically insignificant at the $10 \%$ level or better in all return windows examined. The coefficient on $C I G_{-} S U R P_{i, t} * S I Z E_{-} I N D_{i, t}, \beta_{3}$, is not statistically significant once controlling for macroeconomic information content as proxied for by $H I_{-} M A C R O$. Hence, we provide no evidence that size reflects firm disclosures with more macroeconomic information content incremental to our proxy for macroeconomic information content, $H I \_M A C R O$.

\subsubsection{Forecast Accuracy and Pessimism}

Our analytical framework discussed in section 4.1 allows for the possibility that managers may bias their forecasts based on their incentives. As has been discussed in the prior literature, managerial biasing activities are often conjectured to be associated with lower responses to management disclosures as a result of market participants anticipating the biasing activities of management. Consistent with this conjecture, Rogers and Stocken (2005) find that market-adjusted equity returns for a firm are more positive (less negative) in response to that firm's management forecasts if market participants believe those forecasts are less upwardly biased (i.e., more pessimistic). If we extend this intuition to our analysis, one possible reason for our findings is that our high macro 
forecasts are simply less biased or more accurate, which would suggest that it is not the nature of private information underlying the forecast but the manner in which that information is communicated that matters. As an extreme example, it could be the case that all firms have identically precise underlying macroeconomic information but that the management of high macro firms have less of an incentive to bias their forecasts. That fact that high macro forecasts have lower bias (i.e., are more conservative) and are more accurate is consistent with this possibility.

To assess the likelihood that our high macro variable is solely a proxy for either forecast accuracy or pessimism, we estimate the following regressions:

$$
\begin{aligned}
C R_{i, t} & =\beta_{0}+\beta_{1} H I_{-} M A C R O+\beta_{2} F C S T_{-} I N D+\beta_{3} C I G_{-} S U R P_{i, t} \\
& +\beta_{4} H I_{-} M A C R O * C I G_{-} S U R P_{i, t}+\beta_{5} F C S T_{-} I N D * C I G_{-} S U R P_{i, t} \\
& +\sum \gamma C O N T R O L S+\varepsilon
\end{aligned}
$$

where FCST_IND $\in\{A C C U R A C Y, P E S S I M I S M\}, A C C U R A C Y$ is a binary variable set equal to one if a firm's average earnings guidance accuracy, defined as the absolute value of guidance less realized earnings, is in the highest sample quartile and zero otherwise, and PESSIMISM is a binary variable set equal to one if a firm's average earnings guidance pessimism, defined as guidance less realized earnings, is in the lowest sample quartile and zero otherwise.

In untabulated results of regression (10) for $A C C U R A C Y$, we find that the coefficient on $H I_{-} M A C R O * C I G_{-} S U R P$ is positive and statistically significant at the $1 \%$ level across the ($1,+1),(-1,+3)$, and $(-1,+10)$ announcement period windows $(1.885,2.556$, and 6.338 respectively). Conversely, the coefficients on $A C C U R A C Y * C I G_{-} S U R P$ are all statistically indistinguishable from zero at the $10 \%$ level or better. For PESSIMISM, we find similar results, with the coefficients on $H_{\_} M A C R O * C I G_{-} S U R P$ estimated at 1.463 (statistically significant at the $10 \%$ level), 3.192 (statistically significant at the $5 \%$ level), and 7.794 (statistically significant at the $1 \%$ level) across the three announcement period windows. The coefficients on PESSIMISM*CIG_SURP are all statistically indistinguishable from zero. Hence, our analysis of forecast accuracy and pessimism in conjunction with our proxy for macroeconomic content suggests that our primary results are not attributable to characteristics of firms' earnings guidance rather than their underlying macroeconomic information. 


\subsection{Timing}

In the final set of supplemental analyses, we assess whether the associations we document are attributed to forecasts during particular periods. First, we assess whether there is a significant difference in associations between firms that forecast early in a calendar quarter and late in a calendar quarter. To do so, we re-estimate our primary regressions for firms announcing earnings guidance in the latter half of a calendar quarter and the earlier half of a calendar quarter. We find no significant differences in the association between guidance news and aggregate stock market returns based on when earnings guidance is released during a calendar quarter.

Second, given the observation that i) bad news forecasts tend to garner a larger response than good news forecasts and ii) the 2008 financial crisis was such a significant bad news event, it is conceivable that our results are driven by forecast surprises in 2008. We re-estimate our primary regressions with 2008 observations excluded from our data set and find that the coefficients on CIG_SURP are positive and statistically significant at the $1 \%$ level for high macro firms and statistically indistinguishable from zero at conventional levels for low macro firms.

\section{Conclusion}

The evidence presented in this study suggests that bundled quantitative earnings guidance from bellwether firms, which are defined as those firms for which macroeconomic state realizations explain the greatest variation in their earnings forecasts, provide timely macroeconomic news. The forecasts of such firms are associated with aggregate stock market returns around their forecast announcement window, whereas non-bundled forecasts and the forecasts of non-bellwether firms are not. Further, the bundled forecasts of bellwether firms are associated with the returns of firms inside and outside the forecasting firm's industry, suggesting that the macroeconomic news pertains to shocks affecting many industries as opposed to a single industry. Consistent with prior firm-specific findings on how the market responds to attributes of management forecasts, the aggregate market response to bundled forecasts of bellwether firms is greater for bad news and point forecasts. Finally, changes in market-wide uncertainty, as measured by the VIX, are negatively associated with the bundled forecast of bellwether firms, which corroborates the associations identified for equity prices. 


\section{Appendix}

\section{Macro Factor Derivation Procedure}

1. We first obtain quarterly earnings realizations for all firms for 1995-2008, which correspond to the availability of management forecast data.

2. We then randomly assign firms to 20 portfolios in order to reduce the dimensionality of the earnings series (i.e., more quarters than earnings series).

3. Next, we aggregate firm earnings by each portfolio and quarter to arrive at 1,120 (20 portfolios x 56 quarters) aggregate earnings portfolio quarters.

4. Let the time series of each portfolio represent the variable of interest for factor analysis.

5. Factor analysis is conducted to extract the common variance (or latent structure) across variables that explains the most variance with the fewest variables. We keep three factors on the basis that each explains at least as much variation as a single variable, which cumulatively explain $72 \%$ of the variation in the earnings series. From this, we obtain the time-invariant factor loadings for each variable.

6. Lastly, we "score" the variables by quarter by taking the scalar product of the standardized variables and each factor loading to arrive at a set of factor scores by quarter. The timevariant factors scores (three for each quarter) represent our macroeconomic factor, or $\mathrm{M}$, in our analytic framework. 


\section{References}

Anilowski, C., Feng, M., Skinner, D. J., 2007. Does earnings guidance affect market returns? the nature and information content of aggregate earnings guidance. Journal of Accounting and Economics 44 (1-2), 36-63.

Baginski, S., 1987. Intra-industry information transfers associated with management forecasts of earnings. Journal of Accounting Research 25, 196-216.

Baginski, S. P., Conrad, E. J., Hassell, J. M., 1993. The effects of management forecast precision on equity pricing and on the assessment of earnings uncertainty. The Accounting Review 68 (4), 913-927.

Baker, S. R., Bloom, N., Davis, S. J., 2012. Measuring Economic Policy Uncertainty. Working paper, Stanford University and University of Chicago.

Ball, R., Sadka, G., Sadka, R., 2009. Aggregate earnings and asset prices. Journal of Accounting Research 47 (5), 1097-1133.

Ball, R., Shivakumar, L., 2008. How Much New Information Is There in Earnings? Journal of Accounting Research 46 (5), 975-1016.

Barro, R. J., 1990. The stock market and investment. The Review of Financial Studies 3 (1), $115-131$.

Ben-David, I., Graham, J. R., Harvey, C. R., 2012. Managerial miscalibration. Charles A. Dice Center Working Paper No. 2010-12; Fisher College of Business Working Paper No. 2010-03-012; AFA 2007 Chicago Meetings Paper . Available at SSRN: http://ssrn.com/abstract=1640552.

Beyer, A., Cohen, D. A., Lys, T. Z., Walther, B. R., 2010. The financial reporting environment: Review of the recent literature. Journal of Accounting and Economics 50 (2-3), 296-343.

Black, F., 1976. Studies of stock price volatility. In: Proceedings of the 1976 Meeting of the American Statistical Association, Business and Economic Statistics Section.

Brown, P., Ball, R., 1967. Some preliminary findings on the association between the earnings of a firm, its industry, and the economy. Journal of Accounting Research 5, 55-77.

Campbell, J. Y., 1991. A variance decomposition for stock returns. The Economic Journal 101 (405), $157-179$

Campbell, J. Y., Hentschel, L., 1992. No news is good news: An asymmetric model of changing volatility in stock returns. Journal of Financial Economics 31 (3), 281-318.

Chen, N. F., Roll, R., Ross, S. A., 1986. Economic forces and the stock market. Journal of Business $59(3), 383-403$.

Choi, J. H., Kalay, A., Sadka, G., 2012. Earnings News and Aggregate Stock Returns. Working paper, Columbia University.

Christie, A. A., 1982. The stochastic behavior of common stck variances: Value, leverage and interest rate effects. Journal of Financial Economics 10 (4), 407-432. 
Christofferson, P., Ghysels, E., Swanson, N. R., 2002. Let's get "real" about using economic data. Journal of Empirical Finance 9 (3), 343-360.

Clinch, N. A., Sinclair, G. J., 1987. Intra-industry information releases: A recursive systems approach. Journal of Accounting and Economics 9 (1), 89-106.

Cohen, L., Frazzini, A., 2008. Economic Links and Prdictable Returns. The Journal of Finance 63 (4), 1977-2011.

Cready, W. M., Gurun, U. G., 2010. Aggregate market reaction to earnings announcements. Journal of Accounting Research 48 (2), 289-334.

Dye, R. A., 1985. Disclosure of nonproprietary information. Journal of Accounting Research 23 (1), $123-145$.

Fama, E. F., 1981. Stock returns, real activity, inflation, and money. The American Economic Review 71 (4), 545-565.

Fama, E. F., 1990. Stock returns, expected returns, and real activity. Journal of Finance 45, 10891108.

Flannery, M. J., Protopapadakis, A. A., 2002. Macroeconomic Factors Do Influence Aggregate Stock Returns. The Review of Financial Studies 15 (3), 751-782.

Foster, G., 1981. Intra-industry information transfers associated with earnings releases. Journal of Accounting and Economics 3 (3), 201-232.

French, K. R., Schwert, G. W., Stambaugh, R. F., 1987. Expcted stock returns and volatility. Journal of Financial Economics 19 (1), 3-29.

Hann, R. N., Ogneva, M., Sapriza, H., 2012. Forecasting the Macroeconomy: Analysts versus Economists. Working paper, University of Maryland, Stanford University, and the Board of Governors of the Federal Reserve System.

Hutton, A. P., Lee, L. F., Shu, S., 2012. Do managers always know better? An examination of the relative accuracy of management and analyst forecasts. Journal of Accounting Research 50 (5), $1217-1244$.

Hutton, A. P., Miller, G. S., Skinner, D. J., 2003. The role of supplementary statements with management earnings forecasts. Journal of Accounting Research 41 (5), 867-890.

Kim, K., Pandit, S., Wasley, C. E., 2012. Aggregate uncertainty and the issuance of management earnings forecasts. Working paper, University of Missouri at Columbia, University of Illinois at Chicago, and University of Rochester.

Lang, M., Lundholm, R., 1996. The relation between security returns, firm earnings, and industry earnings. Contemporary Accounting Research 13 (2), 607-629.

Liu, L. X., Zhang, L., 2008. Momentum Profits, Factor Pricing, and Macroeconomic Risk. The Review of Financial Studies 21 (6), 2417-2448.

McCulla, S. H., Smith, S., September 2007. Measuring the economy: A primer on GDP and the national income and product accounts. Bureau of Economic Analysis, U.S. Department of Commerce. 
Milian, J. A., 2010. The Relative Information Content of Guidance and Earnings. Working paper, Florida Internation University.

Pownall, G., Wasley, C., Waymire, G., 1993. The stock price effects of alternative types of management earnings forecasts. The Accounting Review 68 (4), 896-912.

Pownall, G., Waymire, G., 1989. Voluntary disclosure and earnings information transfers. Journal of Accounting Research 27 (Supp), 85-105.

Rogers, J. L., Skinner, D. J., Van Buskirk, A., 2009. Earnings guidance and market uncertainty. Journal of Accounting and Economics 48 (1), 90-109.

Rogers, J. L., Stocken, P. C., 2005. Credibility of Management Forecasts. The Accounting Review 80 (4), 1233-1260.

Rogers, J. L., Van Buskirk, A., 2012. Bundled forecasts in empirical accounting research. Journal of Accounting and Economics, forthcoming.

Sadka, G., 2007. Understanding stock price volatility: the role of earnings. Journal of Accounting Research 45, 199-228.

Schwert, G. W., 1990. Stock returns and real activity: a century of evidence. Journal of Finance $45,1237-1257$.

Shivakumar, L., 2010. Discussion of aggregate market reaction to earnings announcements. Journal of Accounting Research 48 (2), 335-342.

Skinner, D. J., 1994. Why firms voluntarily disclose bad news. Journal of Accounting Research $32(1), 38-60$.

Soffer, L. C., Thiagarajan, S. R., Walther, B. R., 2000. Earnings preannouncement strategies. Review of Accounting Studies 5 (1), 5-26.

Thomas, J. K., Zhang, F., 2008. Overreaction to intra-industry information transfers? Journal of Accounting Research 46 (4), 909-940.

Verrecchia, R. E., 1983. Discretionary disclosure. Journal of Accounting and Economics 5 (179-194).

Vuolteenaho, T., 2002. What drives firm-level stock returns? Journal of Finance 57 (1), 233-264.

Wu, G., 2001. The Determinants of Asymmetric Volatility. The Review of Financial Studies 14 (3), 837-859. 
Figure 1: Histogram of $\frac{r_{s}^{2}}{r_{i}^{2}}-\frac{R_{e}^{2}}{1-R_{e}^{2}}$ from Regressions (3) and (4)

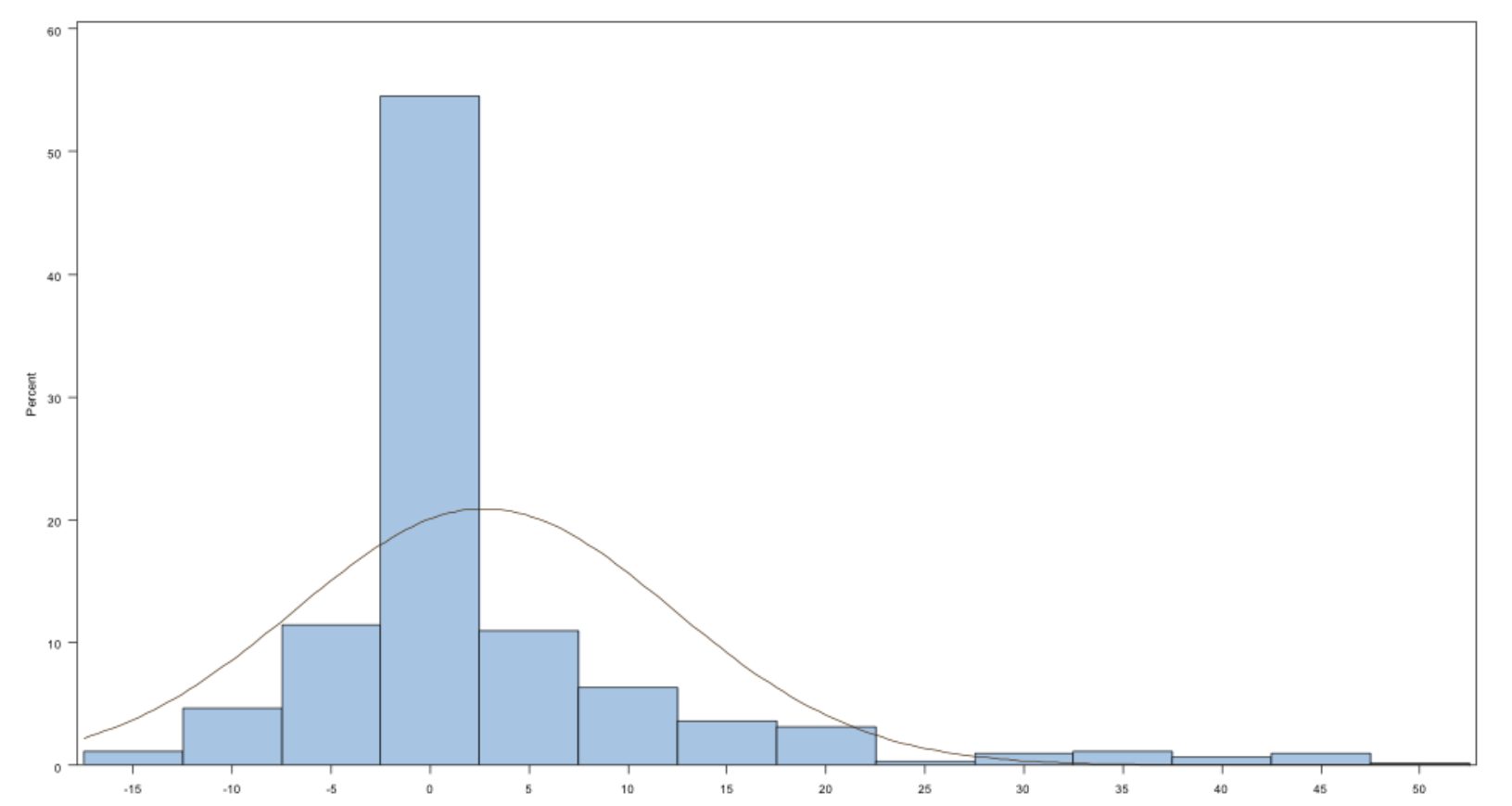

Figure 1 presents the distribution of the differences between the ratio of macroeconomic information in firms' earnings guidance $\left(\frac{r_{s}^{2}}{r_{i}^{2}}\right)$ and the ratio of its underlying historical earnings $\left(\frac{R_{e}^{2}}{1-R_{e}^{2}}\right) \cdot \frac{r_{s}^{2}}{r_{i}^{2}}$ is computed as the semi-partial $R^{2}$ of the estimated macroeconomic factor $\left(r_{s}^{2}\right)$ divided by the semi-partial $R^{2}$ of the estimated firm-specific factor $\left(r_{i}^{2}\right)$ from Regression (4) for explaining variation in earnings guidance. $\frac{R_{e}^{2}}{1-R_{e}^{2}}$ is computed as the $R^{2}$ divided by $1-R^{2}$ from Regression (3) for explaining the sensitivity of a firm's historical earnings to the macroeconomic state variables. 
Figure 2: Histogram of $r_{s}^{2}$ from Regression (4)

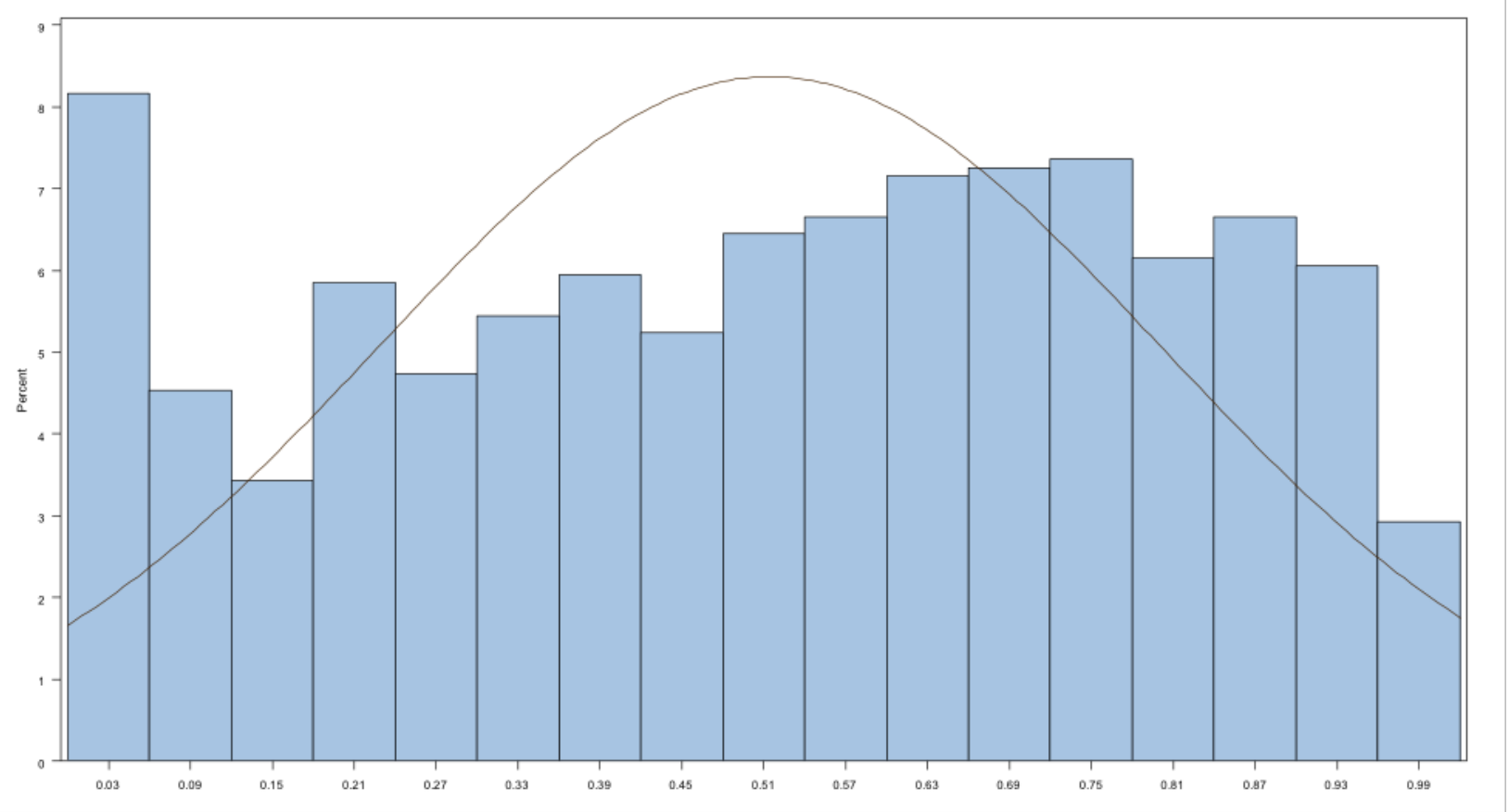

Figure 2 presents the distribution of the estimated macroeconomic information in firms' earnings guidance, $r_{s}^{2}$. 
Company issued earnings guidance surprise (CIG_SURP) is calculated as the actual guidance given by management (CIG_ACTUAL) less the most recent analyst consensus prior to the announcement date scaled by beginning of quarter price. Analyst earnings surprise (ANALYST_SURP) is calculated as realized earnings (EARN_ACTUAL) less the most recent analyst consensus prior to the announcement date scaled by beginning of quarter price. Assets (ASSETS), sales (SALES), and market capitalization (MARKET_CAP) are obtained prior to the announcement date at the beginning of the quarter. The remaining variables are macroeconomic time series (MTS) forecasts made in the quarter prior to the announcement date for the current quarter and are from the Philadelphia Federal Reserve Bank's Survey of Professional Forecasters, where BOND is the level of Moody's AAA corporate bond yield, CPI is the consumer price index inflation rate, HOUSING is the level of housing starts, INDPROD is the level of the index of industrial production, RGDP is the level of real gross domestic product, TBILL is the three-month Treasury bill rate, TBOND is the 10-year Treasury bond rate, and UNEMP is the unemployment rate. Further detail on MTS forecast variable calculations can be found at http://www.philadelphiafed.org.

\begin{tabular}{|c|c|c|c|c|c|c|}
\hline \multicolumn{7}{|c|}{ Panel A - Overall Sample } \\
\hline Variable & $\mathbf{N}$ & Mean & Median & $\begin{array}{l}\text { Standard } \\
\text { Deviation }\end{array}$ & $\begin{array}{c}25 \text { th } \\
\text { Percentile }\end{array}$ & $\begin{array}{c}75 \text { th } \\
\text { Percentile }\end{array}$ \\
\hline \multicolumn{7}{|l|}{ Firm Variables } \\
\hline CIG_SURP & 16,824 & -0.0003 & -0.0003 & 0.0272 & -0.0019 & 0.0009 \\
\hline ANALYST_SURP & 16,824 & -0.0015 & 0.0000 & 0.0389 & -0.0017 & 0.0014 \\
\hline CIG_ACTUAL & 16,824 & 0.35 & 0.27 & 0.38 & 0.11 & 0.50 \\
\hline EARN_ACTUAL & 16,824 & 0.32 & 0.26 & 0.40 & 0.11 & 0.46 \\
\hline ASSETS (\$m) & 16,167 & 1,447 & 391 & 3,898 & 156 & 1,150 \\
\hline SALES $(\$ \mathrm{~m})$ & 16,807 & 1,165 & 240 & 4,366 & 79 & 755 \\
\hline MARKET_CAP (\$m) & 16,824 & 3,100 & 716 & 11,300 & 220 & 2,290 \\
\hline \multicolumn{7}{|l|}{ MTS Variables } \\
\hline BOND & 16,824 & 6.04 & 5.90 & 0.49 & 5.72 & 6.20 \\
\hline CPI & 16,824 & 2.30 & 2.35 & 0.38 & 2.02 & 2.54 \\
\hline HOUSING (m) & 16,824 & 1.65 & 1.68 & 0.27 & 1.55 & 1.87 \\
\hline INDPROD & 16,824 & 122 & 116 & 12 & 113 & 121 \\
\hline RDGP (\$b) & 16,824 & 10,749 & 11,078 & 906 & 9,616 & 11,561 \\
\hline TBILL & 16,824 & 3.00 & 2.92 & 1.53 & 1.67 & 4.61 \\
\hline TBOND & 16,824 & 4.68 & 4.66 & 0.42 & 4.44 & 4.91 \\
\hline UNEMP & 16,824 & 5.26 & 5.23 & 0.54 & 4.76 & 5.84 \\
\hline
\end{tabular}


Panel B - Overall Sample by Macroeconomic Information Content

High Macroeconomic Information Content Firms

\begin{tabular}{lcccccc} 
Variable & N & Mean & Median & $\begin{array}{c}\text { Standard } \\
\text { Deviation }\end{array}$ & $\begin{array}{c}\text { 25th } \\
\text { Percentile }\end{array}$ & $\begin{array}{c}\mathbf{7 5 t h} \\
\text { Percentile }\end{array}$ \\
\hline \hline Firm Variables & & & & & & \\
CIG_SURP & 3,830 & 0.0001 & -0.0003 & 0.0390 & -0.0017 & 0.0004 \\
ANALYST_SURP & 3,830 & -0.0003 & 0.0004 & 0.0389 & -0.0011 & 0.0018 \\
CIG_ACTUAL & 3,830 & 0.29 & 0.22 & 0.35 & 0.09 & 0.42 \\
EARN_ACTUAL & 3,830 & 0.30 & 0.23 & 0.38 & 0.10 & 0.43 \\
ASSETS $(\$ \mathrm{~m})$ & 3,637 & 1,184 & 276 & 3,937 & 124 & 772 \\
SALES $(\$ \mathrm{~m})$ & 3,830 & 863 & 144 & 3,349 & 53 & 391 \\
MARKET_CAP $(\$ \mathrm{~m})$ & 3,830 & 2,170 & 576 & 4,950 & 173 & 1,930 \\
\hline
\end{tabular}

Low Macroeconomic Information Content Firms

\begin{tabular}{lcccccc} 
Variable & N & Mean & Median & $\begin{array}{c}\text { Standard } \\
\text { Deviation }\end{array}$ & $\begin{array}{c}\text { 25th } \\
\text { Percentile }\end{array}$ & $\begin{array}{c}\text { 75th } \\
\text { Percentile }\end{array}$ \\
\hline \hline Firm Variables & & & & & & \\
CIG_SURP & 12,994 & -0.0004 & -0.0003 & 0.0226 & -0.0019 & 0.0014 \\
ANALYST_SURP & 12,994 & -0.0018 & 0.0000 & 0.0389 & -0.0018 & 0.0013 \\
CIG_ACTUAL & 12,994 & 0.37 & 0.29 & 0.39 & 0.12 & 0.52 \\
EARN_ACTUAL & 12,994 & 0.33 & 0.26 & 0.41 & 0.11 & 0.47 \\
ASSETS (\$m) & 12,530 & 1,523 & 436 & 3,883 & 169 & 1,280 \\
SALES $(\$ \mathrm{~m})$ & 12,977 & 1,254 & 284 & 4,620 & 92 & 928 \\
MARKET_CAP $(\$ \mathrm{~m})$ & 12,994 & 3,380 & 762 & 12,500 & 240 & 2,410 \\
\hline
\end{tabular}


Panel C - Industry Breakdown by Macroeconomic Information Content

High Macroeconomic Information Content Firms

\begin{tabular}{lcc} 
Industry & N & Percent \\
\hline Mining & 61 & $2 \%$ \\
Manufacturing & 1,682 & $44 \%$ \\
Transport and Comm. & 115 & $3 \%$ \\
Retail & 366 & $10 \%$ \\
Finance & 199 & $5 \%$ \\
Services & 1,407 & $37 \%$ \\
\hline & 3,830 & $100 \%$
\end{tabular}

Low Macroeconomic Information Content Firms

\begin{tabular}{lcc} 
Industry & N & Percent \\
\hline Agriculture & 10 & $0.1 \%$ \\
Mining & 276 & $2 \%$ \\
Manufacturing & 6,298 & $48 \%$ \\
Transport and Comm. & 547 & $4 \%$ \\
Retail & 2,425 & $19 \%$ \\
Finance & 361 & $3 \%$ \\
Services & 3,048 & $23 \%$ \\
Public Admin. & 27 & $0.2 \%$ \\
\hline & 12,994 & $100 \%$
\end{tabular}


Table 2: The Market Reaction to Guidance

Regression tests on the reaction of several market return windows to company issued guidance surprise (CIG_SURP) for bundled and unbundled forecasts. CR is the cumulative value-weighted market return excluding firm i over the t days surrounding the release of the management forecast. CIG_SURP is calculated as the actual guidance given by management less the most recent analyst consensus prior to the announcement date scaled by beginning of quarter price. ANALYST_SURP is calculated as realized earnings less the most recent analyst consensus prior to the announcement date scaled by beginning of quarter price. The remaining variables are macroeconomic time series (MTS) forecasts made in the quarter prior to the announcement date for the current quarter and are from the Philadelphia Federal Reserve Bank's Survey of Professional Forecasters, where BOND is the level of Moody's AAA corporate bond yield, CPI is the consumer price index inflation rate, HOUSING is the level of housing starts, INDPROD is the level of the index of industrial production, RGDP is the level of real gross domestic product, TBILL is the three-month Treasury bill rate, TBOND is the 10-year Treasury bond rate, and UNEMP is the unemployment rate. Further detail on MTS forecast variable calculations can be found at http://www.philadelphiafed.org. Results below are presented both with and without the MTS forecast control variables.

\begin{tabular}{|c|c|c|c|c|c|c|c|}
\hline \multirow[b]{3}{*}{ Variable } & \multirow{3}{*}{$\begin{array}{c}\text { Predicted } \\
\text { Sign }\end{array}$} & \multicolumn{6}{|c|}{ Dependent Variable } \\
\hline & & & Bundled Forecast & & & bundled Fore & \\
\hline & & CR $(-1,+1)$ & CR $(-1,+3)$ & CR $(-1,+10)$ & CR $(-1,+1)$ & CR $(-1,+3)$ & CR $(-1,+10)$ \\
\hline
\end{tabular}

No MTS Controls

CIG_SURP

ANALYST_SURP

$+$

$\begin{array}{lc}0.796^{* *} & 1.546^{* * *} \\ (0.415) & (0.504) \\ -0.515 & 0.0509 \\ (0.315) & (0.623)\end{array}$

$3.470^{* * *}$
$(0.960)$
0.904
$(1.397)$

\section{$1.085^{*}$}

0.906

$-1.193$

0.0509

(0.805)

(1.206)

(1.911)

With MTS Controls

CIG_SURP

$+$

$\begin{array}{cc}0.598^{*} & 1.416^{* * *} \\ (0.424) & (0.495) \\ -0.540^{* *} & -0.00599 \\ (0.249) & (0.538) \\ -0.877 & -0.668 \\ (0.845) & (1.205) \\ 0.903^{* * *} & 1.107^{* * *} \\ (0.269) & (0.365) \\ 0.484 & 0.894 \\ (0.358) & (0.589) \\ -0.0135 & -0.0246 \\ (0.0156) & (0.0247)\end{array}$

$2.850^{* * *}$
$(1.084)$
0.571
$(1.019)$
$-4.280^{*}$
$(2.382)$
$3.653^{* * *}$
$(0.897)$
$2.149^{*}$
$(1.176)$
-0.0534
$(0.0509)$

0.603
$(0.727)$


-0.792
$(0.779)$
0.386
$(0.375)$
$1.130^{* * *}$
$(0.400)$
-0.0134
$(0.0111)$

$-2.420$

ANALYST_SURP

BOND

CPI

HOUSING

(0.0156)

(0.0247)

(0.0111)

(1.381)

$-3.439^{*}$

(1.995)

$\begin{array}{cc}(0.951) & (1.995) \\ 0.645 & 3.113^{* * *}\end{array}$

(0.600) (1.088)

$1.488^{* * *} \quad 3.009^{* * *}$

(0.461) (0.992)

$-0.0236 \quad-0.0668$

Continued on next page 
Continued from previous page

\begin{tabular}{|c|c|c|c|c|c|c|}
\hline RGDP & $\begin{array}{c}-0.000696^{*} \\
(0.000376)\end{array}$ & $\begin{array}{l}-0.000735 \\
(0.000481)\end{array}$ & $\begin{array}{c}-0.00291^{* * *} \\
(0.00103)\end{array}$ & $\begin{array}{c}-0.000650^{*} \\
(0.000394)\end{array}$ & $\begin{array}{c}-0.000926^{* *} \\
(0.000416)\end{array}$ & $\begin{array}{r}-0.00299^{* * *} \\
(0.000857)\end{array}$ \\
\hline TBILL & $\begin{array}{l}-0.197 \\
(0.160)\end{array}$ & $\begin{array}{l}-0.175 \\
(0.225)\end{array}$ & $\begin{array}{l}-0.910 \\
(0.595)\end{array}$ & $\begin{array}{c}-0.0761 \\
(0.214)\end{array}$ & $\begin{array}{l}-0.117 \\
(0.250)\end{array}$ & $\begin{array}{c}-0.717 \\
(0.520)\end{array}$ \\
\hline TBOND & $\begin{array}{c}0.481 \\
(0.681)\end{array}$ & $\begin{array}{c}0.149 \\
(1.030)\end{array}$ & $\begin{array}{c}2.610 \\
(2.252)\end{array}$ & $\begin{array}{l}0.0330 \\
(0.530)\end{array}$ & $\begin{array}{l}-0.432 \\
(0.680)\end{array}$ & $\begin{array}{c}0.602 \\
(1.580)\end{array}$ \\
\hline UNEMP & $\begin{array}{l}-0.662 \\
(0.517)\end{array}$ & $\begin{array}{c}-0.603 \\
(0.724)\end{array}$ & $\begin{array}{l}-2.016 \\
(1.542)\end{array}$ & $\begin{array}{l}-0.566 \\
(0.565)\end{array}$ & $\begin{array}{l}-0.979 \\
(0.654)\end{array}$ & $\begin{array}{c}-2.556^{* *} \\
(1.166)\end{array}$ \\
\hline Observations & 13,403 & 13,403 & 13,388 & 3,418 & 3,418 & 3,410 \\
\hline R-squared & 0.016 & 0.017 & 0.101 & 0.021 & 0.026 & 0.076 \\
\hline
\end{tabular}

Clustered standard errors (firm and quarter) are provided in parentheses. Statistical significance at the $0.01,0.05$ and 0.10 levels is denoted by $* * *, * *$, and $*$ respectively. 
Table 3: The Guidance of Firms with High Macroeconomic Information Content

This table extends the framework of Table 2 for bundled earnings guidance observations by estimating regressions stacked by an indicator variable (Hi _Macro) for firms considered to possess high macroeconomic information content as defined by those firms in the uppermost quartile of the semi-partial R-squared for the systemic component in Equation (4), or $r_{s}^{2}$. CR is the cumulative value-weighted market return excluding firm $i$ over the $t$ days surrounding the release of the management forecast. CIG_SURP is calculated as the actual guidance given by management less the most recent analyst consensus prior to the announcement date scaled by beginning of quarter price. ANALYST_SURP is calculated as realized earnings less the most recent analyst consensus prior to the announcement date scaled by beginning of quarter price. The remaining variables are macroeconomic time series (MTS) forecasts made in the quarter prior to the announcement date for the current quarter and are from the Philadelphia Federal Reserve Bank's Survey of Professional Forecasters, where BOND is the level of Moody's AAA corporate bond yield, CPI is the consumer price index inflation rate, HOUSING is the level of housing starts, INDPROD is the level of the index of industrial production, RGDP is the level of real gross domestic product, TBILL is the three-month Treasury bill rate, TBOND is the 10-year Treasury bond rate, and UNEMP is the unemployment rate. Further detail on MTS forecast variable calculations can be found at http://www.philadelphiafed.org. Results below are presented both with and without the MTS forecast control variables.

\begin{tabular}{|c|c|c|c|c|c|c|}
\hline \multirow[b]{2}{*}{ Variable } & \multirow{2}{*}{$\begin{array}{l}\text { Predicted } \\
\text { Sign }\end{array}$} & \multicolumn{2}{|c|}{ CR $(-1,+1)$} & \multicolumn{2}{|c|}{$\begin{array}{c}\text { Dependent Variable } \\
\text { CR }(-1,+3)\end{array}$} & CR $(-1,+10)$ \\
\hline & & Hi_MacroIND $=1$ & Hi_MacroIND $=0$ & Hi_MacroIND $=1$ & Hi_MacroIND $=0$ & Hi_Macro $_{I N D}=1 \quad$ Hi_Macro IND $=0$ \\
\hline
\end{tabular}

N $\quad$ No MTS Controls

CIG_SURP $\quad+\quad 1.477^{* * *}$

$(0.264)$

CIG_SURP

ANALYST_SURP

$-0.713$

$(0.664)$

$-0.601^{* * *}$
$(0.0522)$
-0.0689
$(0.442)$

$2.448^{* * *}$

$(0.415)$

$.045^{* * *}$

$(0.445)$

With MTS Controls

CIG_SURP

$1.328 * * *$

(0.358)

CIG_SURP

$-0.668$

(0.708)

0.0570

(0.861)

CPI

$0.834^{* * *}$

(0.442)

0.207

(0.938)

0.0834

$(0.907)$

0.432

(0.862)

$(2.150)$

$2.274^{* * *}$

1.017

(0.843)

(1.804)

ANALYST_SURP

$-0.824$

$(0.566)$

$-0.136$

(0.311)

$-1.161$

$2.306^{* * *}$

(0.307)

$4.408^{* * *}$

(0.776)

$-0.107$

(1.096)

0.142

(1.047)

0.387

(0.749)

0.0928

$-0.896$

(0.882)

(1.324)

(1.174)

$0.989^{* *}$

$1.141^{* * *}$

$\begin{array}{cc} & 0.947 \\ & (2.266) \\ 2.058^{* *} & 0.790 \\ (0.973) & (1.368) \\ -4.783^{*} & -4.117^{*} \\ (2.692) & (2.298) \\ 4.105^{* * *} & 3.517^{* * *}\end{array}$

Continued on next page 
Continued from previous page

\begin{tabular}{|c|c|c|c|c|c|c|}
\hline & $(0.258)$ & $(0.285)$ & $(0.418)$ & $(0.353)$ & (1.012) & $(0.868)$ \\
\hline HOUSING & 0.471 & 0.491 & $1.070^{*}$ & 0.845 & 2.117 & $2.157^{*}$ \\
\hline & $(0.375)$ & $(0.362)$ & (0.638) & $(0.574)$ & (1.299) & (1.143) \\
\hline INDPROD & $\begin{array}{l}-0.0134 \\
(0.0170)\end{array}$ & $\begin{array}{l}-0.0134 \\
(0.0154)\end{array}$ & $\begin{array}{l}-0.0261 \\
(0.0261)\end{array}$ & $\begin{array}{c}-0.0242 \\
(0.0243)\end{array}$ & $\begin{array}{c}-0.0450 \\
(0.0539)\end{array}$ & $\begin{array}{l}-0.0558 \\
(0.0501)\end{array}$ \\
\hline RGDP & $\begin{array}{l}-0.000318 \\
(0.000346)\end{array}$ & $\begin{array}{c}-0.000814^{* *} \\
(0.000405)\end{array}$ & $\begin{array}{l}-0.000492 \\
(0.000519)\end{array}$ & $\begin{array}{c}-0.000811^{*} \\
(0.000473)\end{array}$ & $\begin{array}{c}-0.00322^{* * *} \\
(0.00118)\end{array}$ & $\begin{array}{c}-0.00281^{* * *} * \\
(0.000995)\end{array}$ \\
\hline TBILL & $\begin{array}{c}-0.0645 \\
(0.178)\end{array}$ & $\begin{array}{l}-0.236 \\
(0.166)\end{array}$ & $\begin{array}{l}-0.105 \\
(0.254)\end{array}$ & $\begin{array}{l}-0.195 \\
(0.217)\end{array}$ & $\begin{array}{c}-1.052 \\
(0.686)\end{array}$ & $\begin{array}{l}-0.871 \\
(0.572)\end{array}$ \\
\hline TBOND & $\begin{array}{l}-0.192 \\
(0.763)\end{array}$ & $\begin{array}{c}0.683 \\
(0.689)\end{array}$ & $\begin{array}{l}-0.543 \\
(1.134)\end{array}$ & $\begin{array}{c}0.351 \\
(1.006)\end{array}$ & $\begin{array}{l}2.948 \\
(2.498)\end{array}$ & $\begin{array}{c}2.503 \\
(2.189)\end{array}$ \\
\hline UNEMP & $\begin{array}{l}-0.288 \\
(0.477)\end{array}$ & $\begin{array}{l}-0.778 \\
(0.556)\end{array}$ & $\begin{array}{l}-0.533 \\
(0.731)\end{array}$ & $\begin{array}{l}-0.627 \\
(0.725)\end{array}$ & $\begin{array}{l}-2.334 \\
(1.718)\end{array}$ & $\begin{array}{l}-1.939 \\
(1.511)\end{array}$ \\
\hline Observations & 3,089 & 10,314 & 3,089 & 10,314 & 3,087 & 10,301 \\
\hline R-squared & 0.015 & 0.019 & 0.017 & 0.018 & 0.122 & 0.096 \\
\hline F-test & $2.15^{* *}$ & & $2.41^{*}$ & & $3.46^{*}$ & \\
\hline
\end{tabular}

Clustered standard errors (firm and quarter) are provided in parentheses. The F-test computes the difference between the coefficients on CIG_SURP across the Hi_Macro partition (Hi_Macro IND=1 - Hi_MacroIND=0) from the regressions with MTS controls. Statistical significance at the $0.01,0.05$ and 0.10 levels is denoted by $* * *, * *$, and $*$ respectively 
Table 4: The Impact of Proximity

This table compares the market response to bundled earnings guidance of those firms in close proximity to high macroeconomic information content guidance providers (as defined by 4 digit SIC code, or Within SIC) to firms outside the major SIC division of the guidance firm (Outside Division). CR is the cumulative value-weighted return excluding firm i over the t days surrounding the release of the management forecast. CIG_SURP is calculated as the actual guidance given by management less the most recent analyst consensus prior to the announcement date scaled by beginning of quarter price. ANALYST SURP is calculated as realized earnings less the most recent analyst consensus prior to the announcement date scaled by beginning of quarter price. The remaining variables are macroeconomic time series (MTS) forecasts made in the quarter prior to the announcement date for the current quarter and are from the Philadelphia Federal Reserve Bank's Survey of Professional Forecasters, where BOND is the level of Moody's AAA corporate bond yield, CPI is the consumer price index inflation rate, HOUSING is the level of housing starts, INDPROD is the level of the index of industrial production, RGDP is the level of real gross domestic product, TBILL is the three-month Treasury bill rate, TBOND is the 10-year Treasury bond rate, and UNEMP is the unemployment rate. Further detail on MTS forecast variable calculations can be found at http://www.philadelphiafed.org. Results below are presented both with and without the MTS forecast control variables.

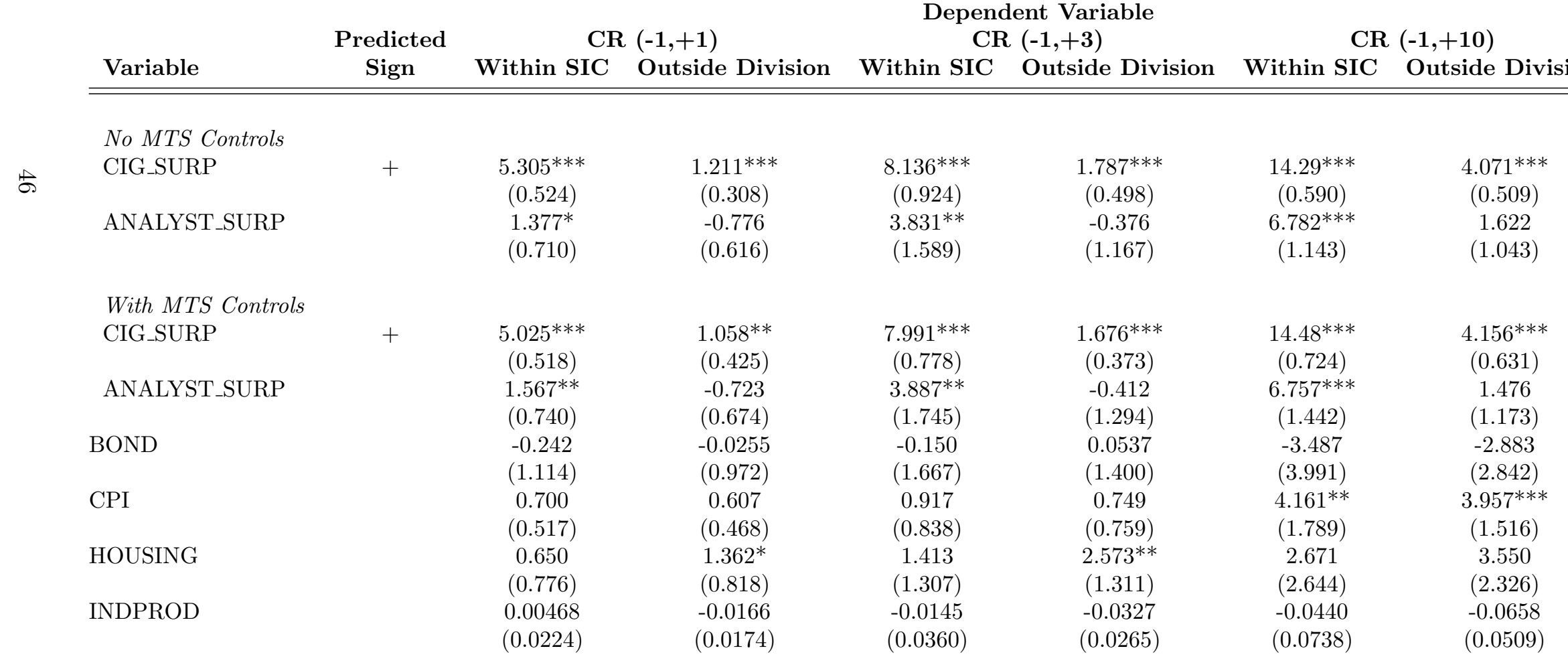

Continued on next page 
Continued from previous page

\begin{tabular}{|c|c|c|c|c|c|c|}
\hline RGDP & $\begin{array}{c}-0.000433 \\
(0.000601)\end{array}$ & $\begin{array}{c}-0.000517 \\
(0.000481)\end{array}$ & $\begin{array}{c}-0.000625 \\
(0.000859)\end{array}$ & $\begin{array}{c}-0.000791 \\
(0.000682)\end{array}$ & $\begin{array}{c}-0.00272 \\
(0.00217)\end{array}$ & $\begin{array}{c}-0.00262^{*} \\
(0.00156)\end{array}$ \\
\hline TBILL & $\begin{array}{c}-0.00110 \\
(0.259)\end{array}$ & $\begin{array}{c}0.0789 \\
(0.225)\end{array}$ & $\begin{array}{c}0.00366 \\
(0.384)\end{array}$ & $\begin{array}{c}0.0792 \\
(0.319)\end{array}$ & $\begin{array}{c}-0.119 \\
(1.002)\end{array}$ & $\begin{array}{c}-0.499 \\
(0.747)\end{array}$ \\
\hline TBOND & $\begin{array}{c}-0.175 \\
(1.054)\end{array}$ & $\begin{array}{c}0.153 \\
(0.833)\end{array}$ & $\begin{array}{c}-0.406 \\
(1.567)\end{array}$ & $\begin{array}{c}0.0144 \\
(1.185)\end{array}$ & $\begin{array}{c}2.059 \\
(3.590)\end{array}$ & $\begin{array}{c}2.786 \\
(2.603)\end{array}$ \\
\hline UNEMP & $\begin{array}{l}-0.260 \\
(1.002)\end{array}$ & $\begin{array}{c}-0.0709 \\
(0.695)\end{array}$ & $\begin{array}{c}-0.289 \\
(1.449)\end{array}$ & $\begin{array}{l}-0.200 \\
(0.988)\end{array}$ & $\begin{array}{c}0.455 \\
(3.090)\end{array}$ & $\begin{array}{l}-0.311 \\
(2.032)\end{array}$ \\
\hline R-squared & 0.018 & 0.035 & 0.024 & 0.048 & 0.069 & 0.169 \\
\hline F-test & $3.96^{* * *}$ & & $6.32^{* * *}$ & & $10.33^{* *}$ & \\
\hline
\end{tabular}

Clustered standard errors (firm and quarter) are provided in parentheses. The F-test computes the difference between the coefficients on CIG_SURP across the proximity partition (Within SIC - Outside Division) from the regressions with MTS controls. Statistical significance at the 0.01, 0.05 and 0.10 levels is denoted by $* * *, * *$, and $*$ respectively. 
Table 5: Forecast Attributes

This table extends the framework of Table 3 on the bundled earnings guidance of high macroeconomic information content firms to examine forecast attributes. Stacked regressions are provided to capture the sign of guidance surprise (POS_SURP) and forecast precision (POINT). Panel A tests the joint reaction to high macroeconomic information content and POS_SURP where POS_SURP is set to one for firms with a positive CIG_SURP and zero otherwise. Panel B examines whether guidance provided by firms with high macroeconomic information content is more informative if provided in the form of a point estimate where POINT is set to one for firms which provide a point estimate and zero otherwise. CR is the cumulative value-weighted market return excluding firm i over the $t$ days surrounding the release of the management forecast. CIG_SURP is calculated as the actual guidance given by management less the most recent analyst consensus prior to the announcement date scaled by beginning of quarter price. ANALYST_SURP is calculated as realized earnings less the most recent analyst consensus prior to the announcement date scaled by beginning of quarter price. The remaining variables are macroeconomic time series (MTS) forecasts made in the quarter prior to the announcement date for the current quarter and are from the Philadelphia Federal Reserve Bank's Survey of Professional Forecasters. The MTS forecast control variables have been suppressed for expositional economy.

Panel A

Variable
Predicted Sign

CR $(-1,+1$
POS_SURP
IND $=1 \quad$ POS

Dependent Variable

$$
\text { CR }(-1,+3)
$$

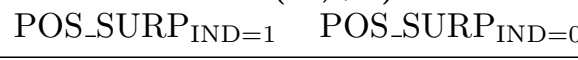

CR $(-1,+10)$

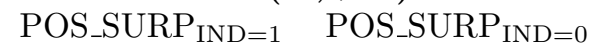

$\infty \quad$ No MTS Controls

\section{CIG_SURP}

ANALYST_SURP

$+$

$1.557^{* * *}$
$(0.261)$
-0.343
$(0.416)$

$1.557 * * *$
$(0.261)$
-0.343

(0.416)

With MTS Controls CIG_SURP

\section{ANALYST_SURP}

$\begin{array}{cc}1.294^{* * *} & 22.11^{* * *} \\ (0.267) & (9.219) \\ -0.337 & -20.01^{* *} \\ (0.435) & (8.755)\end{array}$

$20.79 * * *$
$(8.909)$
$-20.16^{* *}$
$(8.576)$


$22.11^{* * *}$
$(9.219)$
$-20.01^{* *}$
$(8.755)$

2,194

895

R-squared

F-test

\begin{tabular}{lc} 
R-squared & 895 \\
F-test & 0.025 \\
\hline
\end{tabular}

0.016
$20.81^{* *}$

$2.255^{* * *}$
$(0.500)$
0.348
$(0.857)$

$$
\begin{aligned}
& 37.23^{* *} \\
& (16.51) \\
& -20.21^{*} \\
& (11.36)
\end{aligned}
$$

$$
\begin{gathered}
4.824^{* * *} \\
(0.405) \\
2.321^{* * *} \\
(0.695)
\end{gathered}
$$

$-11.27$

(10.08)

$\begin{array}{cccc}2.487^{* * *} & 35.34^{* *} & 4.554^{* * *} & 15.41 \\ (0.732) & (15.89) & (1.165) & (17.29) \\ 0.261 & -21.50^{*} & 2.237^{* * *} & -13.21 \\ (0.896) & (11.43) & (0.776) & (8.413)\end{array}$

(15.89)

$-21.50^{*}$

(11.43)
$4.554^{* * *}$
(1.165)
$2.237^{* * *}$
(0.776)

15.41

(17.29)

$-13.21$

(8.413)

895

0.119

$32.86^{* *}$

10.85

$\begin{array}{cccc}895 & 2,194 & 895 & 2,192 \\ 0.040 & 0.018 & 0.147 & 0.119 \\ & 32.86^{* *} & & 10.85\end{array}$




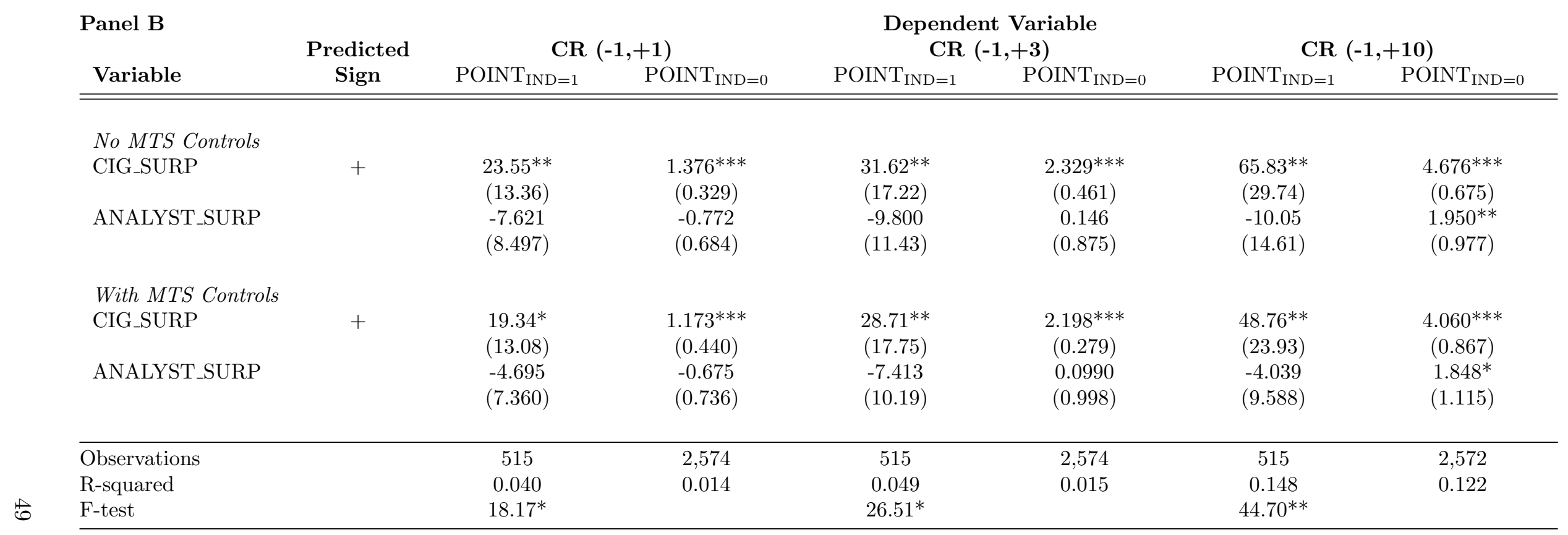

Clustered standard errors (firm and quarter) are provided in parentheses. In Panel A, the F-test computes the difference between the coefficients on CIG_SURP across the surprise partition (POS_SURP ${ }_{I N D=0}-P_{\text {POS_SURP }}$ IND $=1_{1}$ ) from the regressions with MTS controls. In Panel B, the F-test computes the difference between the coefficients on CIG_SURP across the precision partition (Point ${ }_{I N D=1}-$ Point $_{I N D=0}$ ) from the regressions with MTS controls. Statistical significance at the $0.01,0.05$ and 0.10 levels is denoted by $* * *, * *$, and $*$ respectively. 


\section{Table 6: Guidance Surprise and Uncertainty}

This table extends the framework of Table 5, Panel A on the bundled earnings guidance of high macroeconomic information content firms to examine the impact of guidance surprise asymmetry on overall market uncertainty where uncertainty is measured using the Chicago Board Options Exchange Volatility Index, or VIX. VIX is calculated as the change in the value of the index in the $t$ days surrounding the release of the management forecast. CIG_SURP is calculated as the actual guidance given by management less the most recent analyst consensus prior to the announcement date scaled by beginning of quarter price. ANALYST _SURP is calculated as realized earnings less the most recent analyst consensus prior to the announcement date scaled by beginning of quarter price. The remaining variables are macroeconomic time series (MTS) forecasts made in the quarter prior to the announcement date for the current quarter and are from the Philadelphia Federal Reserve Bank's Survey of Professional Forecasters. The MTS forecast control variables have been suppressed for expositional economy.

\begin{tabular}{|c|c|c|c|c|c|}
\hline \multirow[b]{3}{*}{ Variable } & \multirow{3}{*}{$\begin{array}{l}\text { Predicted } \\
\text { Sign }\end{array}$} & \multicolumn{4}{|c|}{ Dependent Variable } \\
\hline & & \multicolumn{2}{|c|}{$\Delta \operatorname{VIX}(-1,0)$} & \multicolumn{2}{|c|}{$\Delta \operatorname{VIX}(-1,+1)$} \\
\hline & & POS_SURP IND $=1$ & POS_SURP IND $=0$ & POS_SURP IND $=1$ & POS_SURP ${ }_{\text {IND }=0}$ \\
\hline \multicolumn{6}{|l|}{ No MTS Controls } \\
\hline \multirow[t]{2}{*}{ CIG_SURP } & - & $-1.485^{* * *}$ & -23.48 & $-1.152^{* * *}$ & $-24.98^{*}$ \\
\hline & & $(0.195)$ & $(19.81)$ & $(0.176)$ & $(15.95)$ \\
\hline \multirow[t]{2}{*}{ ANALYST_SURP } & & -0.0832 & 5.968 & 0.0574 & 19.24 \\
\hline & & $(0.267)$ & $(3.886)$ & $(0.220)$ & $(15.04)$ \\
\hline \multicolumn{6}{|l|}{ With MTS Controls } \\
\hline \multirow[t]{2}{*}{ CIG_SURP } & - & $-1.174^{* * *}$ & $-25.77^{*}$ & $-0.650 * * *$ & $-29.78^{* *}$ \\
\hline & & $(0.0190)$ & $(19.24)$ & $(0.154)$ & $(14.08)$ \\
\hline \multirow[t]{2}{*}{ ANALYST_SURP } & & -0.139 & 5.430 & -0.0153 & 18.24 \\
\hline & & $(0.282)$ & $(4.166)$ & $(0.243)$ & $(15.86)$ \\
\hline Observations & & 895 & 2,194 & 895 & 2,194 \\
\hline R-squared & & 0.021 & 0.012 & 0.021 & 0.017 \\
\hline F-test & & & $-24.60 * *$ & & $-29.13^{* *}$ \\
\hline
\end{tabular}

Clustered standard errors (firm and quarter) are provided in parentheses. The F-test computes the difference between the coefficients on CIG_SURP across the surprise partition (POS_SURP $\mathrm{IND}=0_{-}-\mathrm{POS}_{\mathrm{SU}} \mathrm{PPP}_{\mathrm{IND}=1}$ ) from the regressions with MTS controls. Statistical significance at the $0.01,0.05$ and 0.10 levels is denoted by $* * *, * *$, and $*$ respectively 
Table 7: Forecast Bunching

This table provides supplemental analysis to examine the effect of forecast bunching on the aggregate stock market reaction to high macroeconomic content earnings guidance. The regressions follow the format of those found in Table 3 for High_Macro $I N D=1$ firms and contrast bundled forecasts made during "seasons" and "non-seasons." Observations included in the season sub-sample are management earnings forecasts released during the last ten days of January, April, July, and October. All other forecasts are categorized as non-season. CIG_SURP is calculated as the actual guidance given by management less the most recent analyst consensus prior to the announcement date scaled by beginning of quarter price. ANALYST_SURP is calculated as realized earnings less the most recent analyst consensus prior to the announcement date scaled by beginning of quarter price. The remaining variables are macroeconomic time series (MTS) forecasts made in the quarter prior to the announcement date for the current quarter and are from the Philadelphia Federal Reserve Bank's Survey of Professional Forecasters. Results below are presented with the MTS forecast control variables, which have been suppressed for expositional economy.

\begin{tabular}{|c|c|c|c|c|c|c|c|}
\hline \multirow[b]{2}{*}{ Variable } & \multirow{2}{*}{$\begin{array}{l}\text { Predicted } \\
\text { Sign }\end{array}$} & \multicolumn{2}{|c|}{ CR $(-1,+1)$} & \multicolumn{2}{|c|}{$\begin{array}{c}\text { Dependent Variable } \\
\text { CR }(-1,+3)\end{array}$} & \multicolumn{2}{|c|}{ CR $(-1,+10)$} \\
\hline & & Non-Season & Season & Non-Season & Season & Non-Season & Season \\
\hline CIG_SURP & + & $\begin{array}{c}1.168^{* * *} \\
(0.482)\end{array}$ & $\begin{array}{c}17.95^{* * *} \\
(7.697)\end{array}$ & $\begin{array}{c}1.986^{* * *} \\
(0.714)\end{array}$ & $\begin{array}{c}36.02^{* *} \\
(20.90)\end{array}$ & $\begin{array}{c}3.816^{* * *} \\
(1.310)\end{array}$ & $\begin{array}{l}20.01^{*} \\
(13.38)\end{array}$ \\
\hline ANALYST_SURP & & $\begin{array}{l}-0.399 \\
(0.593)\end{array}$ & $\begin{array}{c}-9.965^{* *} \\
(5.064)\end{array}$ & $\begin{array}{c}0.571 \\
(0.695)\end{array}$ & $\begin{array}{c}-16.74^{* *} \\
(7.398)\end{array}$ & $\begin{array}{c}2.366^{* *} \\
(0.959)\end{array}$ & $\begin{array}{l}-1.855 \\
(10.89)\end{array}$ \\
\hline Observations & & 1,532 & 1,557 & 1,532 & 1,557 & 1,530 & 1,557 \\
\hline R-squared & & 0.057 & 0.030 & 0.124 & 0.027 & 0.178 & 0.213 \\
\hline F-test & & & $16.79 *$ & & $34.03^{*}$ & & 16.20 \\
\hline
\end{tabular}

Clustered standard errors (firm and quarter) are provided in parentheses. The F-test computes the difference between the coefficients on CIG _SURP across the season partition ('Season' - 'Non-Season') from the regressions with MTS controls. Statistical significance at the $0.01,0.05$ and 0.10 levels is denoted by ***, **, and ${ }^{*}$ respectively. 